\title{
Thermal Residual Stress Analysis of Epoxy Bimaterial Laminates and Bonded
}

\section{Joints.}

\author{
F.S. Jumbo ${ }^{1}$, I.A. Ashcroft ${ }^{1 *}$, A.D. Crocombe ${ }^{2}$ and M.M Abdel Wahab ${ }^{2}$ \\ ${ }^{1}$ Wolfson School of Mechanical and Manufacturing Engineering, Loughborough \\ University, Loughborough, LE11 3TU, UK
}

${ }^{2}$ School of Engineering, University of Surrey, Guildford, GU2 7XH, UK

\begin{abstract}
Finite element analysis (FEA) and continuum mechanics techniques have been used to model the thermal residual stress distribution in bonded joints and assess the suitability of using two-dimensional (2D) analysis methods. The methods are first employed to investigate stresses in metal-epoxy bi-material strip samples. The change in curvature of two bi-material strip systems during heating and cooling in a dry atmosphere were measured and this behaviour was successfully modelled using both FEA and continuum mechanics techniques. 2D and 3D FEA analyses were compared with the experimental results to determine the most accurate and efficient method of predicting the thermal residual stresses. It was found that none of the analytical solutions or 2D FEA approximations were fully able to describe the 3D stress state in the strip. The incorporation of geometric and material non-linearity into the models was also found to be necessary to obtain accurate results. The effects of creep were also considered, but the analyses showed that the thermal residual stresses in the bi-material strips were too low for significant relaxation due to creep. The validated computational methods were then used to predict the thermal residual stresses in bonded single lap joints and double lap joints. The thermal stresses were found to be highest in joints with dissimilar adherends. Measurements of thermal strains in the joints with dissimilar adherends using neutron diffraction were compared with the finite element predictions and good agreement was observed, providing further validation of the computational predictive methods.
\end{abstract}

\footnotetext{
* Corresponding author. Email: i.a.ashcroft@lboro.ac.uk
} 


\section{Introduction}

The different mechanical and thermal properties of the constituents of adhesive joints results in thermal residual stresses when the joint cools from the cure temperature. These thermal residual stresses add to the mechanical stresses arising from externally applied loads and can cause premature failure of the adhesive bonds. In order to efficiently design an adhesive joint, a quick and precise method for the estimation of the stress and deformation states for various boundary conditions is necessary.

The effects of thermal residual stresses on crack growth behaviour in adhesive joints have been studied previously [1,2] and residual stresses have been shown to have a negative effect on the fracture properties of an adhesive [3-5]. The factors that will influence the extent of the residual stresses include; volume changes during curing, material properties of the joint system, geometry of the constraining fixture and dimensional changes due to thermal contraction or expansion [2,6-8]. Residual stresses also play a critical role in premature failure in conjunction with fatigue, creep, wear and stress enhanced degradation.

From an engineering viewpoint, quick and accurate prediction and optimisation of adhesive joint strength is desirable and to this end analytical, numerical and experimental methods have been used to investigate the thermal residual stresses in adhesive joints. FEA has been used to study the thermo-mechanical behaviour of bonded joints, however, most researchers have employed 2D rather than 3D FEA models because the 2D models are computationally efficient. However, studies [9, 10] have shown that the results from 2D models can be misleading, especially for thermal loading conditions. A number of experimental approaches have also been used to characterise thermal stresses and strains including;

- photo-elastic techniques, which are limited to transparent materials,

- neutron diffraction, which can measure internal strains but suffers from limits on spatial resolution and beam time limits [11-12],

- moiré interferometry and strain gauge techniques, which are used to measure surface strains [11-16]

- X-ray diffraction methods, which can be used to measure near surface strains and

- embedded optical Fibre Bragg Grating (FBG) sensors [17]. 
The curvature in bi-material samples is commonly used as a simple measure of residual stress [18-21], however, the experimentally measured deflection has to be analysed in order to calculate the stresses and strains [22,23]. Yu et al [24] used steel-epoxy adhesive bi-material strip experiments to investigate residual due to shrinkage of the adhesive on curing (curing stresses), differential thermal contraction of adhesive and adherend on cooling from the curing temperature (thermal stresses) and expansion of the adhesive on absorption of atmospheric moisture (hygroscopic stresses). The curing stresses were found to be negligible, which was attributed to the high relaxation of the partly cured adhesive at elevated temperatures. The stress free temperature of the cured strip was found to be slightly higher than the cure temperature, indicating a small degree of post-curing. It was noted that both curing stresses and post cure effects could be accounted for by determining thermal stresses based on the experimentally determined stress-free temperature.

In this work, analytical and numerical methods are used to investigate thermal residual stresses in bi-material strips. The analytical methods used are those of Oel and Frechette [19] and Timoshenko [25]. Three different geometric approximations were investigated for the 2D analyses, namely, plane strain (PE), plane stress (PS) and generalised plane strain (GPE). The plane stress approximation assumes that the stresses induced are in the $\mathrm{x}-\mathrm{y}$ plane and that $\mathrm{z}$-component stresses are not significant. The plane strain approximation assumes that there is no strain in the z-direction, since it can be argued that the sample width is high compared to the thickness, and thus predicts high tensile stresses in the z-direction. The generalised plane strain approximation is able to relieve some of the out of plane constraint imposed by the plane strain model by allowing uniform straining out-of-plane using an additional degree of freedom. This approximation however, does not produce any transverse shear strains. The predictions with the 2D approximations were compared with results from full 3D FEA in order to consider the effects of out-of-plane bending deformations induced by thermal expansion mismatch and an investigation was undertaken to determine the most accurate and efficient prediction of the thermal residual stresses by the use of 2D models. 
The effects of geometric non-linearity were also investigated with creep and temperature dependent material properties incorporated into the models. After application to the bi-material samples, the FE models were applied to single and double lap joints. In these joints, the geometry of the overlap area differs from the typical geometry of the bi-material strips which correspond to $\mathrm{L}>\mathrm{W}>\mathrm{T}$ whereas the lap joints corresponds to $\mathrm{W}>\mathrm{L}>\mathrm{T}$ where $\mathrm{L}, \mathrm{W}$ and $\mathrm{T}$ are respectively the length, width and thickness of the overlap area.

\section{Material Properties}

The mechanical and thermal properties for the metal adherends used in the experimental programme are shown in Table 1 [26-28]. Table 2 shows the properties for the Unidirectional IM7/8552 carbon reinforced polymer (CFRP) used in the double lap joints. The properties for the CFRP are from the literature [29] and in-house testing. The temperature dependent material properties for the adhesives are shown in Table 3. The modulus of elasticity data is from the manufacturer's datasheets [30,31]. The coefficient of thermal expansion was measured using dilatometry in which the length of a bulk sample of material was measured as a function of temperature. The value given in the table was determined by heating between 20 and $100^{\circ} \mathrm{C}$. The Poisson's ratios for FM300-2M and FM73 are 0.38 and 0.4 respectively. The glass transition temperatures ( $\mathrm{T}_{\mathrm{g}}$ ) of the FM73 and FM300 have been quoted as 99 and $144^{\circ} \mathrm{C}$, respectively $[32,33]$.

Creep of the adhesives after cooling from the cure temperature was investigated using the creep analysis procedure in MSC.Marc using the following creep power law

$$
\dot{\bar{\varepsilon}}^{c r}=A \sigma^{n} t^{m}
$$

Where $\dot{\bar{\varepsilon}}^{c r}$ is the equivalent creep strain rate, $\sigma$ is the equivalent stress, $t$ is time and $A, n, \& m$ are creep constants derived from experiments. Integrating Eq. (1) leads to:

$$
\bar{\varepsilon}^{c r}=\frac{A}{m+1} \sigma^{n} t^{m+1}
$$


Where $\bar{\varepsilon}^{c r}$ is the equivalent creep strain. The creep constants used at room temperature are shown in Table 3 and are derived from the work carried out by Althof [34] on creep of FM73 and from characterisation work undertaken by Al-Ghamdi [35] on FM300-2M adhesive.

\section{Bi-material strip analysis}

\subsection{Bi-material strips}

Two bi-material strip systems were considered. The first system consisted of an AISI 302 steel adherend and FM300-2M adhesive. The second bi-material system consisted of a 1050-H18 aluminium adherend and FM73 adhesive. Their dimensions and deflected shapes are summarised in Table 4 , where $\delta$ is the maximum deflection of the strip. In both cases, the steel was prepared by grit blasting and degreasing and the adhesive was cured under pressure at $120^{\circ} \mathrm{C}$. The stress free temperatures, as determined by heating a cured bi-material strip until curvature disappeared, were 123 and $120^{\circ} \mathrm{C}$ for the FM300 and FM73 adhesives, respectively. The small increase in the stress free temperature above the curing temperature for the FM300 was attributed to post cure effects by $\mathrm{Yu}$ et al [24]. According to da Silva and Adams [5], the stress free temperature should be the $\mathrm{T}_{\mathrm{g}}$ for an adhesive that has been heated above a $\mathrm{Tg}$ that is below the curing temperature. The fact that the measured stress free temperature for the FM73 was the curing temperature throws doubt on the previously stated Tg for this adhesive. The measured stress free temperatures were used in the thermal stresses calculations, thus also accounting for any curing stresses or post cure effects, as described in [24].

\subsection{Oel and Frechette theory}

According to this work [19], the thermal strain at a point separated by a distance $x$ from the interface in layer $i$ is given by:

$$
\varepsilon_{i}=\frac{n_{i}-x}{r_{0}}
$$


where $n_{i}$ is the distance separating the neutral surface in layer $i$ from the material interface and is given by:

$$
\begin{aligned}
& n_{1}=\frac{S_{2} d_{2}^{2}+4 S_{1} d_{1}^{2}+3 S_{1} d_{1} d_{2}}{-6 S_{1}\left(d_{1}+d_{2}\right)} \\
& n_{2}=\frac{S_{1} d_{1}^{2}+4 S_{2} d_{2}^{2}+3 S_{2} d_{1} d_{2}}{6 S_{2}\left(d_{1}+d_{2}\right)}
\end{aligned}
$$

where suffix 1 and 2 refer to the two materials of the bi-material strip and:

$$
S_{i}=\frac{E_{i} d_{i}}{1-v_{i}}
$$

where $d_{i}$ is the thickness, $v_{i}$ is the Poisson's ratio.

At the interface:

$$
\varepsilon_{1}-\varepsilon_{2}=\frac{n_{1}-n_{2}}{r}=\left(\alpha_{1}-\alpha_{2}\right) \Delta T
$$

where $\varepsilon_{\mathrm{i}}$ is the thermal strain, $r$ is the radius of curvature, $\alpha_{\mathrm{i}}$ is the coefficient of thermal expansion and $\Delta T$ is the change in temperature.

From Eqs. (3) to (7), it is possible to predict the radius of curvature of the bi-material strip at any temperature if the elastic and thermal properties of the two materials are known. Alternatively, the coefficient of thermal expansion of one of the materials can be calculated if the radius of curvature is known, together with the coefficient of thermal expansion of the other material and the elastic properties of both. After this, it is a simple matter to calculate the variation in longitudinal stress or strain through the bimaterial strip and the maximum deflection of the strip.

\subsection{Timoshenko beam and plate theories}

Another method of calculating the strip deflection is the Timoshenko cantilever beam solution for bi-material thermostats [25] where two material layers with thicknesses $\left(d_{1}\right.$ $\left.\& d_{2}\right)$ which have different thermal expansion coefficients $\left(\alpha_{1} \& \alpha_{2}\right)$ and different elastic 
moduli $E_{1} \& E_{2}$ undergo a temperature change of $\Delta T$ that generates an internal bending moment in the strip. The radius of curvature, $r$, of the strip, assuming that the width of the strip is very small is given by:

$$
r=\frac{\left(\frac{d_{1}+d_{2}}{2}\right)+\frac{2\left(E_{1} I_{1}+E_{2} I_{2}\right)}{d_{1}+d_{2}} \times\left(\frac{1}{E_{1} d_{1}}+\frac{1}{E_{2} d_{2}}\right)}{\left(\alpha_{1}-\alpha_{2}\right) \Delta T}
$$

Where $I_{1}$ and $I_{2}$ are the $2^{\text {nd }}$ moments of area of the strips per unit width.

The maximum deflection of the strip is given by;

$$
\delta=\frac{3\left(\alpha_{1}-\alpha_{2}\right) \Delta T\left(d_{1}+d_{2}\right) L^{2}}{4 d_{2}^{2}\left[4+6\left(\frac{d_{1}}{d_{2}}\right)+4\left(\frac{d_{1}}{d_{2}}\right)^{2}+\left(\frac{E_{1}}{E_{2}}\right)\left(\frac{d_{1}}{d_{2}}\right)^{3}+\left(\frac{E_{2}}{E_{1}}\right)\left(\frac{d_{2}}{d_{1}}\right)\right]}
$$

where $\delta$ is the deflection of the strip and $L$ is the length of the bi-material strip. However, the b-imaterial strips used in this study may be considered as plate geometries due to their high width-to-thickness ratios, as shown in Table 3 and this means that the internal bending moment per unit length generated by the change in temperature is of the same magnitude in the longitudinal and transverse directions and there is curvature of the neutral axes in each direction. Eqs. (8) and (9) can be converted to apply to plate geometries by replacing $E_{1} \& E_{2}$ with their respective bi-axial moduli, $E_{1} /\left(1-v_{1}\right)$ and $E_{2} /\left(1-v_{2}\right)[25,36]$.

The predicted deflections from the analytical solutions for a $100^{\circ} \mathrm{C}$ temperature change are presented in Table 5 and are compared with the experimentally measured deflections $(\delta)$ for each bi-material laminate. For the steel/FM300-2M bi-material strip, the results from all the analytical methods show reasonably good agreement with the experimental result. The results from the A1/FM73 bi-material strip, however, show that none of the theoretical analyses can accurately predict the maximum deflection of the strip. This suggests that the accuracy of the predictions from the analytical methods decrease as the length to width ratio decreases. Comparing both plate and beam theory predictions, the plate theory prediction is slightly higher than the beam theory prediction in each case. 
This is because the plate theory includes terms for the transverse radius of curvature, which is neglected by the beam theory, thus making the deflection predicted by plate theory a combination of both longitudinal and transverse deflections.

\subsection{D and 3D FEA predictions}

Finite element analysis (FEA) was carried out using the commercial software MSC.Marc. The bi-material strips were modelled in 2D with 8-node quadratic quadrilateral elements and in 3D with 20 node brick elements and 8-node 3D shell elements. Reduced integration was used for the 2D and 3D brick elements and, using symmetry, only half of the bi-material strip was modelled for the $2 \mathrm{D}$ models and a quarter for the 3D model. The boundary conditions for the models are shown in Fig. 1, illustrating the use of symmetry in the longitudinal direction, and the meshes used in the models can be seen in Fig. 2. In all cases, mesh refinement was continued until the maximum deflection of the strips differed by no more than $2 \%$. Plane strain, plane stress and generalised plane strain conditions were assumed for the 2D models and boundary conditions were chosen to simulate free deformation. Uniform cooling (i.e. no thermal gradients) was assumed for all the models. Transient creep phenomena were ignored as creep was considered only after cooling down from cure, owing to the short timescales during the cool down period. The FEA models were used to investigate the following:

- Curvature of the bi-material strips compared with the experimental and continuum mechanics analyses.

- Effect of geometric \& material non-linearity on the curvature and thermal residual stress distribution in the b-imaterial strips

- Thermal residual stress distribution across the thickness of the bi-material strip

- Most accurate 2D approximation of the 3D stress state.

Geometric linear and non-linear finite element analyses were carried out on the 2D and 3D models using both temperature-independent and temperature-dependent material properties. For the geometric non-linear analyses, the large displacement and updated Lagrange procedure parameters in MSC. Marc were specified. This is suitable for the analysis of problems with large rotations but with small strains. An initial condition of $120^{\circ} \mathrm{C}$ was applied to the models and a uniform cooling rate was applied for a change in temperature of $100^{\circ} \mathrm{C}$. A summary of the analysis options used is presented in Table 6 . 
Note that as the predicted stresses were predominantly below the yield stress for both adherend and adhesive, material linearity was assumed in all the analyses.

\subsubsection{Steel/FM300-2M bi-material strip}

The FEA predictions of maximum deflection for the steel/FM300-2M bi-material strip with a thermal load of $100^{\circ} \mathrm{C}$ are presented in Table 7 . The results from the FEA comparisons show interesting trends for the various analysis cases. The comparisons for case I show the direct FEA comparison with the analytical results since, like the analytical models, they are both geometric linear and temperature independent. The plane stress model predicts a similar deflection to the beam theory and Oel \& Frechette method while the GPE model is similar to the plate theory. Predictions using the plane strain model are very high because of the contribution of the large out-of-plane stresses $\left(\sigma_{\mathrm{zz}}\right)$ generated, since the out-of-plane strain for the model is zero, as shown by the equation below, for each bi-material constituent:

$$
\sigma_{z z}=\frac{E}{(1+v)(1-2 v)}\left[\varepsilon_{x x}+\varepsilon_{y y}-(1+v) \alpha \Delta T\right]
$$

In Eq. 10, the last term in the equation dominates for large changes in temperature.

Case II introduces geometric non-linearity. The deformed shape in case II is updated incrementally throughout the temperature history, resulting in a significantly different displaced shape when compared to Case I. It can be seen that this improves the prediction of the plane strain and plane stress models, but the 3D models underestimate the experimental deflection. The GPE model prediction for Case II is very different from case I and is now similar to the plane strain model. Geometric non-linearity also affects the prediction of the other models, causing a reduction in the predicted displacement. The combination of geometric non-linearity and temperature-dependent elastic modulus in Case III results in only slightly different deflections to Case II, with the plane stress and 3D models showing the best comparison to the experimental value.

The difference in the deflection prediction of the GPE model between Case I and Case II can be explained by reference to the significantly different stress states for each case. This can be seen by comparing the longitudinal $\left(\sigma_{\mathrm{xx}}\right)$ and transverse $\left(\sigma_{\mathrm{zz}}\right)$ stresses near the interface region in the adherend for all 3 cases, as shown in Fig. 3(a) and 3(b), where 
the $\mathrm{x}$ and $\mathrm{y}$ directions are as indicated in Figs. 1 and 2. Whilst the predicted longitudinal stresses increase only slightly in magnitude with increased non-linearity, the transverse stresses decrease sharply with the addition of geometric non-linearity. A direct comparison of the longitudinal stresses in the geometric and material linear models is presented in Fig. 4. The GPE and PS model predictions compared with the calculated stresses from the analytical methods across the thickness of the adhesive are shown in Fig. 4(a) and across the adherend thickness in Fig. 4(b). It can be seen that the stresses are higher in the steel, because of its higher modulus of elasticity and that there is a linear variation of stress through each material. The stress distributions also emphasize the bending phenomena, with the stress in the adherend varying from tensile in the outer region to compressive at the interface, clearly induced by the bending of the beam. It is also clear that the GPE model predicts the same longitudinal stress as the Oel \& Frechette and plate theory while the PS model predicts the same distribution as the beam theory. This is expected as the corresponding FE models are based on similar assumptions and predict similar maximum deflections.

When the predictions from all the FE models are compared, as shown in Fig. 5(a) for the adhesive, the GPE model compares well with the 3D model at the centre of the sample, with the plane strain model predicting slightly higher stresses than the GPE model. The predicted stresses from the 3D model at the edge of the sample show a non-linear variation through the thickness, being similar to the plane stress prediction close to the free surface but increasing close to the interface. This can be attributed to the three dimensional free edge effect, previously reported by Tsai \& Morton [37, 38], who compared $2 \mathrm{D}$ and $3 \mathrm{D}$ predictions of stress at the edges of bimetallic laminates, where they noticed a three-dimensional phenomenon, not present in the 2D or Timoshenko solution. Fig. 5(b) shows the FE model predictions across the thickness of the steel adherend. The GPE prediction compares well with the 3D model at the centre, while the PE model predicts slightly higher stresses. The PS model predictions compare well with the 3D model at the free edge.

\subsubsection{Aluminium/FM73 bi-material strip}

Table 5 shows the analytical and experimental deflections for the Aluminium/FM73 bimaterial strip with a thermal load of a $100^{\circ} \mathrm{C}$ and it can be seen that the analytical 
models all underestimate the experimental deflections, with the Oel \& Frechette method showing the worst prediction. The maximum deflection predictions from the FE models are shown in Table 8. For Case I, all the models underestimate the deflection except the plane strain model, which overestimates the deflection. The inclusion of geometric nonlinearity in Case II improves the prediction of all except the plane stress model. With the addition of temperature dependent material properties in Case III, the GPE and 3D models show very comparable results with the experimentally measured deflection. Results from the analytical longitudinal stress $\left(\sigma_{x x}\right)$ calculations across the bi-material strip thickness in the middle of the strip at room temperature are shown in Fig. 6 for Case I. The stress distributions for the plate theory and Oel and Frechette theory show good agreement with the GPE predictions in the adhesive and adherend and the plane stress model shows good agreement with the beam theory results.

Figs. 7(a) and 7(b) show the Case I longitudinal stress $\left(\sigma_{x x}\right)$ comparison for all FE models and it can be seen that the stress distributions of the GPE and PE models closely match the 3D model in the centre. The stress distribution at the edge from the 3D analysis shows the three-dimensional edge effects previously seen in the steel/FM3002M bi-material strip and a similar relationship to the results from the PS model. From these results, it is clear that the Timoshenko beam analysis and the plane stress model are deficient in the prediction of stresses in the strips as they ignore the effect of stresses developed in the $z$-direction.

\subsubsection{Effect of geometric and material non-linearity}

The effect of geometric non-linearity on the displaced shape is illustrated using the Al/FM73 bi-material strip. The deflected shape of the bi-material sample is shown in Fig. 9(a) and it can be seen that the profile is not entirely cylindrical as there is bending in the width direction close to the ends of the strip. Comparison of the predicted bending profiles from Case III and Case I (Figs. 8(b) and 8(c) respectively) clearly shows the effect of geometric non-linearity, which updates the displaced shape and distributed load throughout the solution process. The experimental bending profile in Fig. 8(a) is very close to that generated by the full non-linear FEA model in Fig. 8(b) and is notably different from the displaced shape in Fig. 8(c), from the geometric linear model. The non-linear bending profile also shows bending in the width direction, which is especially 
noticeable in the low $\mathrm{L} / \mathrm{W}$ ratio samples. This illustrates that although some of the linear models adequately predict the maximum deflection of bi-material strip they cannot accurately describe the full-deformed shape. The effect of temperature dependent properties can be seen in Fig. 9, which shows the evolution of the predicted deflection with temperature for the various GPE models. It is clear that a combination of temperature dependency and large displacement/updated Lagrangian formulation is necessary for the FE models to predict an accurate deformed shape and bending profile.

The effect of geometric non-linearity on the predicted stresses in the bi-material strip at maximum deflection was investigated using the 3D solid model for the Al/FM73 bimaterial strip. Figure 10(a) compares the various predicted adhesive longitudinal stresses $\left(\sigma_{\mathrm{xx}}\right)$ at the edge of the sample and Figure 10(b) compares the longitudinal stresses $\left(\sigma_{\mathrm{xx}}\right)$ at the mid-plane of the strip width along the length of the strip. Owing to the combination of large displacement and small strain, it was interesting to obtain stress results from the local element coordinates and compare them to the global element coordinate results. This clearly demonstrates the need to use local coordinates when reporting stresses in samples subjected to large rotations when using geometric nonlinear FEA. The figures also show that the stress distribution from the geometric linear model is significantly different to that from the geometric non-linear model, especially close to the edges. This can be attributed to the large displacements and rotations of the strip in the longitudinal direction. The effects of singularities at the left edge of the bimaterial strip length can also be seen.

\subsubsection{Effect of creep}

The effect of creep in the bi-material strips after cooling down from cure was investigated using the creep analysis procedure in MSC.Marc. The analyses were carried out using a full non-linear GPE model for a total creep time of 168 hours. The results are shown in Fig. 11, which compares the von Mises stress across the length of the adhesive immediately after cooling down from cure and after the creep period. The results suggest that the stresses in the adhesives are too low for observable creep to occur at room temperature. The predicted deflection is also unchanged after the creep analysis, which agrees with experimental observation of the bi-material specimen under similar conditions. 


\section{FEA predictions of thermal stress in bonded joints}

Thermal residual stresses in lap joints were investigated using similar techniques to those used in the FEA of the bi-material beam samples. In all cases a decrease in temperature, $\Delta \mathrm{T}$, of $-100^{\circ} \mathrm{C}$ was used, to represent cooling from the cure temperature to a representative operating temperature. The configurations of the single and double lap joints analysed in this work are shown in Fig. 12. The single lap joints had 7075 T6 aluminium alloy adherends of $3.125 \mathrm{~mm}$ thickness, which were bonded with the FM73 adhesive. The double lap joint comprised of 7075-T6 aluminium alloy and CFRP (IM7/8552 unidirectional) adherends and FM73 adhesive. The properties of the adherends and adhesive used in the models are given in Tables 1-3. Typical finite element meshes for the joints are shown in Fig. 13(a), for the 2D models, Fig. 13(b) for the fillet area and Fig. 13(c) for the 3D models. The size and shape of the fillet for the FEA models were obtained from measurements of the fillet area using high-resolution photography of the lap joint specimens. The spew was not explicitly controlled when manufacturing the joints, however, as the film adhesive was cut accurately to size and the joints carefully assembled, good repeatability was seen in the fillet dimensions. The average dimensions from five representative joints were determined and used in all the FEA models. The most important area in terms of meshing was the adhesive layer, particularly at the overlap ends. The mesh density was greatest here, as it was important to be able to model the distribution of stresses in the high stress areas of the adhesive. Areas of the substrates away from the adhesive layer were of less importance and the mesh density was reduced in these zones. Owing to symmetry conditions, only half of the single lap joint and a quarter of the double lap joint were modelled in 3D using 8node brick elements with assumed strain formulation. The assumed strain formulation improves the bending characteristics of lower order elements [37]. The global-local structural zooming function in MSC.Marc [38] was used in the overlap area to improve modelling of the stress distribution in critical areas.

\subsection{Aluminium single lap joint}

Comparisons of the stress distributions were taken from the middle of the adhesive thickness to avoid the effects of stress concentrations close to the singularity at the embedded adherend corner. Stresses in the adhesive for the 3D model are evaluated 
along profile 'A-A' shown in Fig. 14(a), and profile 'B-B' shown in Fig. 14(b), for the front edge and centre respectively. Stresses in the 2D models are evaluated along similar profiles. Figs. 15(a) and 15(b) show a comparison of the longitudinal and transverse stresses $\left(\sigma_{\mathrm{xx}} \& \sigma_{\mathrm{zz}}\right)$ in the adhesive using the different FE models considered. The plane stress model underestimates $\sigma_{\mathrm{xx}}$ compared to the $3 \mathrm{D}$ model at the edge and is of course unable to predict $\sigma_{\mathrm{zz}}$. The generalised plane strain model compares well with the 3D model at the centre of the joint in both cases. The plane strain model results in a slightly higher prediction of $\sigma_{\mathrm{xx}}$ and a significantly higher prediction of $\sigma_{\mathrm{zz}}$. The stress distributions in the fillet areas (about $1 \mathrm{~mm}$ from each end), are also of interest. A peak is visible, approximately in the middle of fillet area, followed by a drop at the point where the two adherends overlap each other.

The predicted maximum principal stresses and von Mises equivalent stresses are shown in Fig. 16. The plane strain model overestimates the prediction of the 3D models at the centre by about $20 \%$ while the plane stress model underestimates the $3 \mathrm{D}$ stresses at the edge, also by about $20 \%$. The generalised plane strain model however predicts the same stress as the $3 \mathrm{D}$ model at the centre for both the maximum principal stress and the equivalent stress. It can also be noted that the shape of the principal stress distribution, as predicted by the plane stress model in the fillet area is similar to the $3 \mathrm{D}$ model at the edge, whilst the plane strain and GPE results closely resemble that of the 3D model at the centre. The stress distributions across the overlap width for the $3 \mathrm{D}$ model are evaluated along profile 'C-C' shown in Fig. 14(c). The variations in longitudinal and transverse stress across the width are shown in Fig. 17 and it can be seen that the stress is practically constant across most of the width, reducing close to the free edge.

\subsection{CFRP/AI/FM73 double lap joint}

The stress distributions are compared in the adhesive along profiles A-A in Fig. 18(a) and profile 'B-B' in Fig. 18(c), for the front edge and centre of the joint respectively. Fig. 19 shows the longitudinal stress comparisons, and for $\sigma_{\mathrm{xx}}$, the GPE model compares well with the 3D stress state in the middle of the joint but the plane strain model predicts lower stresses. The plane stress model however compares very well with the $3 \mathrm{D}$ stress state at the edge, except in the fillet area, which is notably different to the trends seen in 
the other joints. Comparison of the transverse stresses show that the plane strain model prediction is higher than the 3D and GPE models, and this is consistent with other joints.

Owing to the difference in the thermal expansion properties of the joint constituents, the peel stress $\left(\sigma_{\mathrm{yy}}\right)$ and shear stress $\left(\tau_{\mathrm{xy}}\right)$, which are negligible in the single lap joints, were also examined and the comparisons are shown in Fig. 20. Fig. 20(a) shows that the highest peel stresses from the 3D model at the edge of the joint, particularly at the right hand side of the overlap area, whilst the 2D models seem to underestimate the peel stresses. The 2D and 3D models compare favourably in the shear stress comparison, shown in Fig. 20(b), with the plane strain model predicting slightly higher stresses. A significant level of shear stresses is observed, as high as $18 \mathrm{MPa}$ near the left hand fillet and about the same in the opposite direction in the right hand fillet area. Comparisons of the maximum principal and von Mises stresses are shown in Fig. 21. It is noticeable that the magnitudes of the stresses are much higher than in the single lap joints because of the difference in adherend materials. The plane strain model slightly overestimates the von Mises stress levels from the 3D stress state.

\section{Validation of thermal residual stresses}

The predicted thermal stresses in the bonded joints were validated using results from neutron diffraction experiments carried out using the ENGIN-X diffractometer at the ISIS spallation source in the Rutherford Appleton Laboratory, UK. Further details of the experiments can be seen in the work of Jumbo et al. [12]. Thermal residual strains were measured using the neutron diffraction method on a CFRP/Al/FM73 double lap joint and the results were compared with the residual strain predictions from 3D FE models. Figure 30 shows the calculated and measured longitudinal $\&$ peel residual strains in the Al/CFRP joint for different positions along the middle line of the outer aluminium adherends. Within the accuracy limits, reasonable agreement is observed between the measured and FEA predicted strains for longitudinal strain as shown in Figure 22(a) and for the peel strains as presented in Figure 22(b). The maximum predicted longitudinal residual strain of $4.5 \times 10^{-3}$ agrees well with the measured values at the middle of the joint length $(\mathrm{x} \sim 6 \mathrm{~mm})$ and equates to a stress of $\sim 32 \mathrm{MPa}$ in the adherends. 


\section{Discussion}

The investigation of thermal residual stresses in epoxy-metal bi-material strips using continuum mechanics, 2D and 3D FEA models was able to characterize the basic requirement for the accurate modelling of thermal residual stresses. A bi-material strip configuration was chosen for initial experiments because the measurement of curvature in the strips provides a simple experimental validation of the modelling methods. Comparisons of the curvature of the strips and stresses through the thickness of the strip indicated that the plane stress and continuum mechanics methods were good at predicting the deflection and stresses in a bi-material strip with a high length-to-width ratio but were poor at predicting the curvature of a strip with a low length-to-width ratio, while the plane strain and generalised plane strain models do a better job of predicting the curvature of a thicker and shorter specimen. This was relevant to the lap joints used in this study, as the length-to-width ratio of the overlap area is very low, meaning that only the plane strain and generalised plane strain approximations are appropriate for modelling thermal stresses using 2D FEA. However, none of the 2D approximations can fully capture the 3D stress state over the whole of the strip, especially the threedimensional edge effects seen. Comparisons of FEA predictions with experimental results showed that the experimental curvature can only be accurately predicted with the inclusion of temperature dependent material properties and geometric non-linearity as linear models do not capture the true bending of the bi-material strips.

The analysis of thermal residual stresses in the single and double lap joints with $2 \mathrm{D}$ and 3D FEA models, using the methods developed from the bimaterial strip analyses show that the levels of thermal residual stress in the CFRP/A1/FM73 double lap joint are significantly higher than the levels of longitudinal, transverse and shear stresses present in the single lap joints, owing to the presence of three dissimilar materials with different thermo-mechanical properties. Areas of high stress concentration near the free ends of the adhesive are also predicted. The 2D model predictions show that the plane strain (PE) model is unsuitable for modelling thermal stresses, as it predicts erroneously high stresses in the transverse direction $\left(\sigma_{\mathrm{zz}}\right)$, because of the constraint imposed by the plane strain assumption. The most appropriate 2D approximation at the centre of the joint is 
the generalised plane strain (GPE) model for all the joints considered, although this is still not wholly appropriate for characterising the complete 3D stress state.

\section{Summary}

Continuum mechanics analysis, 2D and 3D FEA models have been used to evaluate the thermal residual stresses in bi-material strips in order to determine the most appropriate FEA model and further thermal residual stress analyses have been performed on simple lap joints. The following conclusions can be made.

The continuum mechanics analyses and plane stress models were good at predicting the deflection of a strip with a high length to width ratio but poor at predicting the defelection of a strip with a smaller length to width ratio, in which the plane strain and GPE FEA models are more appropriate. The bending profile of the bi-material strips are predicted correctly only with the inclusion of geometric and material non-linearity and this indicates that non-linear analyses are required, as linear models do not capture the true bending of the structures.

For the linear analyses, the Oel \& Frechette method and plate theory gave an excellent fit to the residual stresses predicted by the generalised plane strain and 3D model at the centre, while beam theory results matched the plane stress model. None of the $2 \mathrm{D} \mathrm{FE}$ models can fully predict the 3D stress state over the whole of the strip, especially the three-dimensional edge effects. From the creep analysis, it is clear that there is no significant creep in the adhesive in the bi-material strips at room temperature, which is consistent with experimental results.

The investigation of residual stresses in the lap joints with $2 \mathrm{D}$ and $3 \mathrm{D}$ models shows that the generalised plane strain model compares favourably with the $3 \mathrm{D}$ model at the centre of the joint for all the joints considered and the analyses also showed that there are areas of high stress concentration near the adhesive free ends compared to the rest of the adhesive. However, the plane strain model predicts unusually high stresses in the transverse axial direction due to the constraint imposed by the model and the plane stress model is incapable of predicting stresses in that direction. Of all the joints analysed, the 
predictions of thermal residual stress in the CFRP/Al/FM73 DLJ were highest owing to the different thermo-mechanical properties of the joint constituents.

In general, the thermal residual strains from the finite element analysis showed good agreement with the neutron diffraction results, within the limits of experimental error, for the CFRP/A1/FM73 double lap joint.

\section{Acknowledgements}

The authors are grateful to QinetiQ for funding this work and to Gerry Swallowe \& Pablo Ruiz of Loughborough University for their experimental work on strain measurement using neutron diffraction.

\section{References}

1. Fleck NA, Hutchinson JW, Suo Z. Crack path selection in a brittle adhesive. Int J Sol Struct 1991; 27: 1683-1703.

2. Daghhiyani HR, Ye L, Mai YW. Effect of thermal residual stresses on the crack path adhesively bonded joints. J Mater Sci 1996; 31: 2019-2028.

3. Kemal Apalak M, Gul Apalak Z, Gunes R, Sinan Karakas E. Steady-state thermal and geometrically non-linear stress analysis of an adhesively bonded tee joint with double support. Int J Adhes Adhes 2003; 23: 115-130.

4. Kemal Apalak M, Gunes R, Fidanci L. Geometrically non-linear thermal stress analysis of an adhesively bonded tubular single lap joint. Finite Elem Anal Des 2003; 39: 155-174.

5. da Silva LFM, Adams RD. Joint strength predictions for adhesive joints to be used over a wide temperature range. In J Adhes Adhes 2007; 27: 362-379.

6. Adams RD, Coppendale J, Mallick V, Al-Hamdan H. The effect of temperature on the strength of adhesive joints. Int J Adhes Adhes 1992; 12: 185-190.

7. Ashcroft IA, Nelson LJ, Shaw SJ. Effect of the Environment and Loading Rate on the Mechanical Properties of an Epoxy Film Adhesive. 6th Int Conf Adhesion and Surface Analysis. 2000: Loughborough University.

8. Humsfield GR, Dillard DA. Residual stress development on adhesive joints subjected to thermal cycling. J Adhes 1998; 65: 277-306. 
9. Jumbo F, Ashcroft IA, Crocombe AD, Wahab MA. The analysis of thermal residual stresses in adhesively bonded joints. 7th European Adhesion Conference. 2004. Freiburg.

10. Jumbo F, Ashcroft IA, Crocombe AD, Wahab MA. Modelling of hygro-thermal residual stresses in adhesively bonded joints. 9th Int Conf on the Sci and Technol of Adhesives. 2005. Oxford: Publ. IOM Communications.

11. Ruiz P, Jumbo F, Seaton A, Huntley JM, Ashcroft IA, Swallowe GM. Numerical and experimental investigation of 3-Dimensional Strains in Adhesively Bonded Joints, J Strain Anal 2006; 41: 583-596.

12. Jumbo F, Ruiz PD, Yu Y, Ashcroft IA, Swallowe G, Huntley JM. Experimental and numerical investigation of mechanical and thermal residual strains in adhesively bonded joints. Strain 2007; 43: 1-13.

13. Ruiz P, Jumbo F, Huntley JM, Ashcroft IA, Swallowe GM, Experimental and numerical and investigation of strain distribution within the adhesive layer in bonded joints. Strain. In Press.

14. Crocombe AD, Ong AD, Chan CY, Abdel-Wahab MM, Ashcroft IA. Investigating fatigue damage evolution in adhesively bonded structures using backface strain measurement. J Adhes 2002; 78: 745-778.

15. Graner-Solana A, Crocombe AD, Wahab MA, Ashcroft IA. Fatigue initiation in adhesively bonded single lap joints. J Adhes Sci Tech 2007; 21: 1343-1357.

16. Shenoy V, Ashcroft IA, Critchlow GW, Crocombe AD, Abdel Wahab MM. An investigation into the crack initiation and propagation behaviour of bonded single lap joints using backface strain. Int J Adhes Adhes 2009; 29: 361-371.

17. Colpo F, Humbert L, Giaccari P, Botsis J. Characterization of residual strains in an epoxy block using an embedded FBG sensor and the OLCR technique. Comp Part A: Appl Sci Manuf 2006; 37: 652-661.

18. Gunnars J, Wiklund U. Determination of growth-induced strain and thermoplastic properties of coatings by curvature measurements. Mater Sci Eng A, 2002; 336: 7-21.

19. Oel J, Frechette VD. Stress Distribution in Multiphase Systems: 1, Composites with Planar Interfaces. J Amer Ceram Soc 1976; 50: 542-549.

20. Moore TD, Larvis JL. A simple and fundamental design rule for resisting delamination in bimaterial structures. Microelectronics Reliability 2003; 43: 487494. 
21. Gall K, West N, Spark K, Dunn ML, Finch DS. Creep of thin film Au on immaterial Au/Si microcantilevers. Acta Mater 2004; 52: 2133-2146.

22. Liljedahl CDM, Crocombe AD, Wahab MA, Ashcroft IA. The effect of residual strains on the progressive damage modelling of environmentally degraded adhesive joints. J Adhes Sci Technol 2005; 19: 525-547.

23. Loh, W.K., Crocombe, A.D., Abdel Wahab, M.M and Ashcroft, I.A., Modelling anomalous moisture uptake, swelling and thermal characteristics of a rubber toughened epoxy. Int J Adhes Adhes 2005; 25: 1-12.

24. Yu Y, Ashcroft IA, Swallowe G. An experimental investigation of residual stresses in an epoxy-steel laminate. Int J Adhes Adhes 2006; 26: 511-519.

25. Timoshenko S. Analysis of bi-metal thermostats. J Opt Soc Amer 1925; 11: 233255.

26. MatWeb Data Sheet for AISI Type 302 Steel. 2005, Matweb Material Property Data. Available from: http://www.matweb.com.

27. MatWeb Data Sheet for Aluminum 7075-T6; 7075-T651 2005, Matweb Material Property Data. Available from: http://www.matweb.com.

28. MatWeb Data Sheet for Aluminum 1050-H18 2005, Matweb Material Property Data. Available from: www.matweb.com.

29. Krueger R, Paris IL, O'Brien TK, Minguet PJ. Fatigue life methodology for bonded composite skin/stringer configurations. NASA/TM-2001-210842, ARLTR-2432, National Aeronautics and Space Administration, Langley, Virginia 2001.

30. Cytec, FM73 Toughened Epoxy Film. 1998, Cytec Engineering Materials Inc. Available from: http://www.cytec.com.

31. Cytec, FM300-2 Modified Epoxy Resin Film. 1998, Cytec Engineering Materials Inc. Available from: http://www.cytec.com.

32. Jurf RA. Environmental effect on fracture of adhesively bonded joints. ASTM STP 1988; 981: 276-288.

33. Kohli DK. Improved $121 \mathrm{~V}$ curing epoxy film adhesive for composite bonding and repair applications: FM300-2 adhesive system. Int J Adhes Adhes 1999; 19: 231-42.

34. Althof W. Creep recovery and relaxation of shear loaded adhesive bondlines. J Reinf Plast Compos 1982; 1: 29-39. 
35. Al-Ghamdi AH. Fatigue and creep in DCB Joints. Ph.D. Thesis, Wolfson School of Mech Manuf Eng 2004, Loughborough University, Loughborough, UK.

36. Roark RJ. Roark's Formulas for stress and Strain. 7th ed, ed. Young WC. 2001: McGraw-Hill Professional. 137-139.

37. Tsai MY, Morton J. The stresses in a thermally loaded bimaterial interface. Inter J Sol Struct 1991; 28: 1053-1075.

38. Tsai MY, Morton J. A stress analysis of a thermally loaded bimaterial interface: A localized hybrid analysis. Mech Mater 1992; 13: 117-130.

39. MSC.Software. MSC.Marc 2005r3 Documentation Volume B: Element Library. 2005.

40. MSC.Software. MSC.Marc 2005r3 Documentation Volume A: Theory and User Information. 2005. 
Table 1. Material properties for metal substrates

\begin{tabular}{cccc}
\hline Property & $\begin{array}{c}\text { AISI 302 } \\
\text { Steel }\end{array}$ & $\begin{array}{c}\text { 1050-H18 } \\
\text { Aluminium }\end{array}$ & $\begin{array}{c}\text { 7075-T6 } \\
\text { Aluminium }\end{array}$ \\
\hline Elastic Modulus, $[\mathrm{GPa}]$ & 200 & 72.4 & 71.7 \\
Yield Strength, [MPa] & 275 & 145 & 503 \\
Ultimate tensile strength, [MPa] & 655 & 160 & 572 \\
Poisson's ratio & 0.3 & 0.33 & 0.33 \\
Coefficient of thermal expansion, $\left[{ }^{\circ} \mathrm{C}^{-1}\right]$ & $1.1 \times 10^{-5}$ & $2.25 \times 10^{-5}$ & $2.25 \times 10^{-5}$ \\
\hline
\end{tabular}

Table 2. Material properties for IM7/8552 unidirectional CFRP at $20^{\circ} \mathrm{C}$

\begin{tabular}{|c|c|c|c|c|c|c|c|}
\hline \multicolumn{2}{|c|}{$\begin{array}{c}\text { Elastic } \\
\text { moduli } \\
(\text { GPa })\end{array}$} & \multicolumn{2}{|c|}{$\begin{array}{l}\text { Poisson's } \\
\text { ratios }\end{array}$} & \multicolumn{2}{|c|}{$\begin{array}{c}\text { Failure strengths } \\
(\mathrm{MPa})\end{array}$} & \multicolumn{2}{|c|}{$\begin{array}{c}\begin{array}{c}\text { Coefficients of } \\
\text { thermal expansion } \\
{\left[{ }^{\circ} \mathbf{C}^{-1}\right]}\end{array} \\
\end{array}$} \\
\hline $\mathrm{E}_{11}$ & 165 & $v_{12}$ & 0.30 & $\begin{array}{l}\text { Longitudinal } \\
\text { tensile }\end{array}$ & 2600 & $\alpha_{11}$ & $0.06 \times 10^{-5}$ \\
\hline $\mathrm{E}_{22}$ & 10.6 & $v_{21}$ & 0.021 & $\begin{array}{l}\text { Longitudinal } \\
\text { compressive }\end{array}$ & 1500 & $\alpha_{22}$ & $3.0 \times 10^{-5}$ \\
\hline $\mathrm{E}_{33}$ & 10.6 & $v_{23}$ & 0.487 & $\begin{array}{c}\text { Transverse } \\
\text { tensile }\end{array}$ & 60 & $\alpha_{33}$ & $3.0 \times 10^{-5}$ \\
\hline $\mathrm{G}_{12}$ & 5.12 & $v_{32}$ & 0.487 & $\begin{array}{l}\text { Transverse } \\
\text { compressive }\end{array}$ & 290 & & \\
\hline $\mathrm{G}_{13}$ & 5.12 & $v_{13}$ & 0.3 & Shear & 90 & & \\
\hline $\mathrm{G}_{32}$ & 3.92 & $v_{31}$ & 0.021 & & & & \\
\hline
\end{tabular}


Table 3. Material properties for FM73 and FM300-2M adhesives

\begin{tabular}{ccc}
\hline Property & FM300-2M & FM73 \\
\hline Elastic Modulus at $20^{\circ} \mathrm{C},[\mathrm{GPa}]$ & 2.44 & 2.37 \\
Elastic Modulus at $60^{\circ} \mathrm{C},[\mathrm{GPa}]$ & 1.78 & 1.26 \\
Elastic Modulus at $80^{\circ} \mathrm{C},[\mathrm{GPa}]$ & 1.45 & 0.94 \\
Elastic Modulus at $120^{\circ} \mathrm{C},[\mathrm{GPa}]$ & 0.78 & 0.63 \\
Coefficient of thermal expansion, $\left[{ }^{\circ} \mathrm{C}^{-1}\right]$ & $5.8 \times 10^{-5}$ & $7.9 \times 10^{-5}$ \\
Creep coefficient $(\mathrm{A})$ at $20{ }^{\circ} \mathrm{C}$ & $1.096 \times 10^{-5}$ & $1.63 \times 10^{-22}$ \\
Creep stress exponent (n) at $20^{\circ} \mathrm{C}$ & 1.1077 & 12.16 \\
Creep time exponent $(\mathrm{m})$ at $20{ }^{\circ} \mathrm{C}$ & -0.9857 & -0.6650 \\
\hline
\end{tabular}

Table 2. Configurations and dimensions of bi-material strips investigated

\begin{tabular}{|c|c|}
\hline FM300-2/AISI 312 steel bi-material strip. & Dimensions [mm] \\
\hline$\delta$ & $\begin{array}{l}\text { Adhesive thickness: } 0.26 \\
\text { Adherend thickness: } 0.13 \\
\text { Strip length: } 180 \\
\text { Strip width: } 12\end{array}$ \\
\hline \multicolumn{2}{|l|}{ FM73/1050-H18 aluminium bi-material strip. } \\
\hline$\delta$ & $\begin{array}{l}\text { Adhesive thickness: } 0.32 \\
\text { Adherend thickness: } 0.10 \\
\text { Strip length: } 120 \\
\text { Strip width: } 24\end{array}$ \\
\hline
\end{tabular}

Table 3. Predicted and experimental deflections of bi-material strips with $\Delta T=100^{\circ} \mathrm{C}$. Difference between theoretical and experimental analysis results given in parenthesis.

\begin{tabular}{|c|c|c|c|c|}
\hline & $\begin{array}{c}\text { Experimental } \\
{[\mathrm{mm}]}\end{array}$ & $\begin{array}{c}\text { Beam theory } \\
{[\mathrm{mm}]}\end{array}$ & $\begin{array}{c}\text { Plate theory } \\
{[\mathrm{mm}]}\end{array}$ & $\begin{array}{c}\text { Oel \& Frechette } \\
{[\mathrm{mm}]}\end{array}$ \\
\hline
\end{tabular}




\begin{tabular}{|c|c|c|c|c|}
\hline Steel/FM300-2M & 29.93 & $\begin{array}{c}31.14 \\
(+4 \%)\end{array}$ & $\begin{array}{c}32.50 \\
(+8.5 \%)\end{array}$ & $\begin{array}{c}31.17 \\
(+4.1 \%)\end{array}$ \\
\hline Al/FM73 & 39.09 & $\begin{array}{c}33.03 \\
(-16 \%)\end{array}$ & $\begin{array}{c}33.25 \\
(-15 \%)\end{array}$ & $\begin{array}{c}30.31 \\
(-22 \%)\end{array}$ \\
\hline
\end{tabular}

Table 4. FEA analysis options

Case Analysis Options

Case I Geometric linear and temperature independent material properties

Case II Geometric non-linear and temperature independent material properties

Case III Geometric non-linear and temperature dependent material properties 
Table 5. FEA maximum deflection predictions for steel/FM300-2M bi-material strip with $\Delta T=100^{\circ} \mathrm{C}$

\begin{tabular}{cccccc}
\hline & $\begin{array}{c}\text { PE } \\
{[\mathbf{m m}]}\end{array}$ & $\begin{array}{c}\text { GPE } \\
{[\mathbf{m m}]}\end{array}$ & $\begin{array}{c}\text { PS } \\
{[\mathbf{m m}]}\end{array}$ & $\begin{array}{c}\text { 3-D Solid } \\
{[\mathbf{m m}]}\end{array}$ & $\begin{array}{c}\text { 3-D Shell } \\
{[\mathbf{m m}]}\end{array}$ \\
\hline Case I & 45.89 & 33.52 & 31.38 & 33.53 & 33.62 \\
Case II & 41.08 & 40.41 & 29.99 & 27.27 & 28.44 \\
Case III & 41.52 & 40.80 & 30.00 & 27.15 & 30.20 \\
Experiment & & & $\mathbf{2 9 . 9 3}$ & & \\
\hline
\end{tabular}

Table 6. FEA maximum deflection values for aluminium/FM73 bi-material strip with $\Delta T=100^{\circ} \mathrm{C}$

\begin{tabular}{cccccc}
\hline & $\begin{array}{c}\text { PE } \\
{[\mathbf{m m}]}\end{array}$ & $\begin{array}{c}\text { GPE } \\
{[\mathbf{m m}]}\end{array}$ & $\begin{array}{c}\text { PS } \\
{[\mathbf{m m}]}\end{array}$ & $\begin{array}{c}\text { 3-D Solid } \\
{[\mathbf{m m}]}\end{array}$ & $\begin{array}{c}\text { 3-D Shell } \\
{[\mathbf{m m}]}\end{array}$ \\
\hline Case I & 48.04 & 33.58 & 33.04 & 34.82 & 34.92 \\
Case II & 38.56 & 37.66 & 29.81 & 35.96 & 35.86 \\
Case III & 41.56 & 40.57 & 33.13 & 39.75 & 38.99 \\
Experiment & & & $\mathbf{3 9 . 0 9}$ & & \\
\hline
\end{tabular}



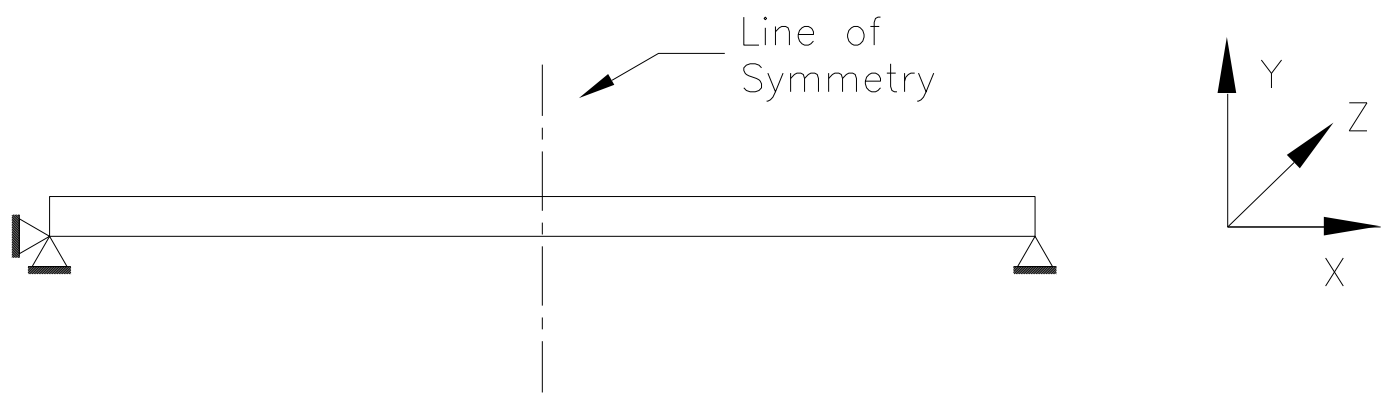

(a)

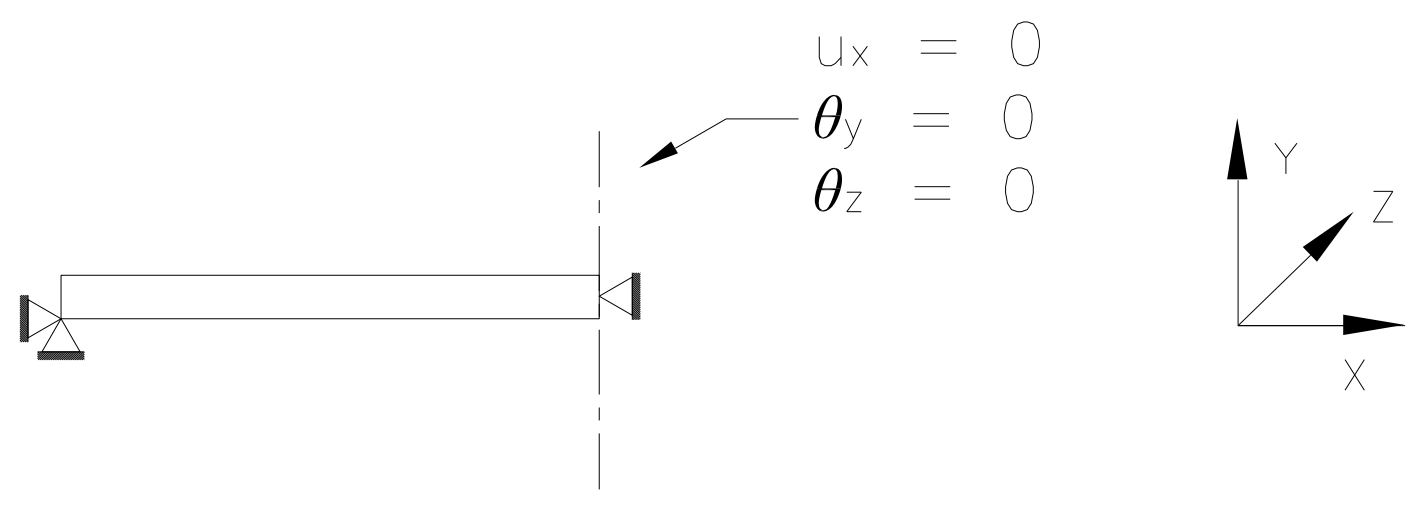

(b)

Figure 1. Longitudinal symmetry used to simplify the bi-material strip model. 


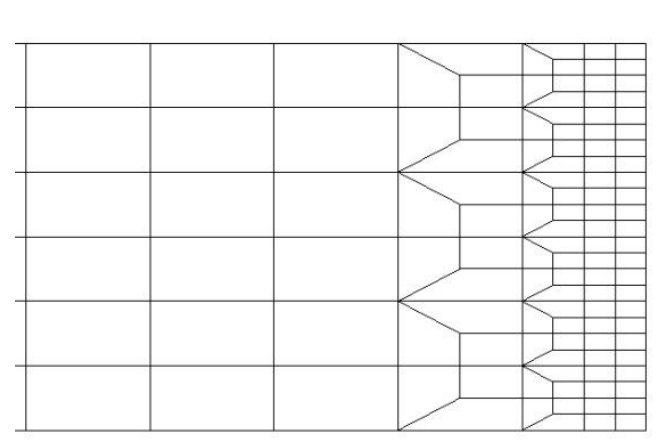

Line of

symmetry

(a)

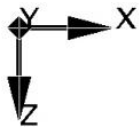

(b)

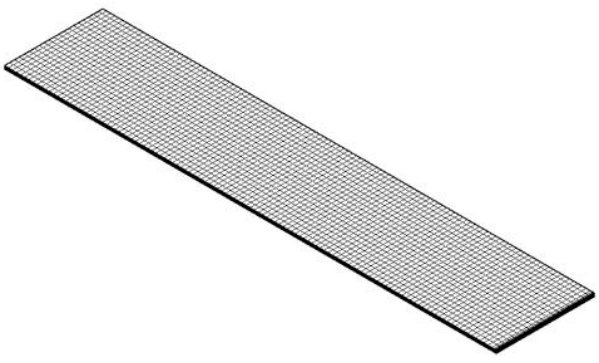

(c)

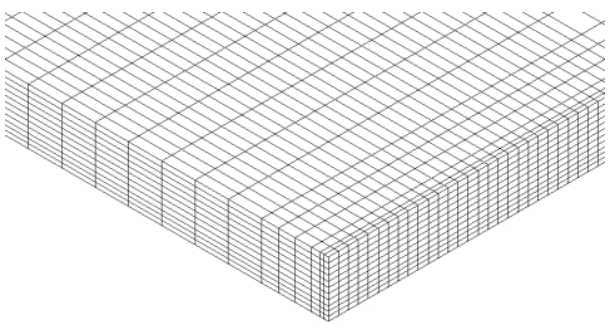

(d)

Figure 1. Bi-material FE meshes: (a) 2D planar (detail of half model, edge view), (b) shell (quarter model, plan view), (c) 3D (quarter model, isometric view) and (d) magnification of 3D mesh at the middle of the strip. 


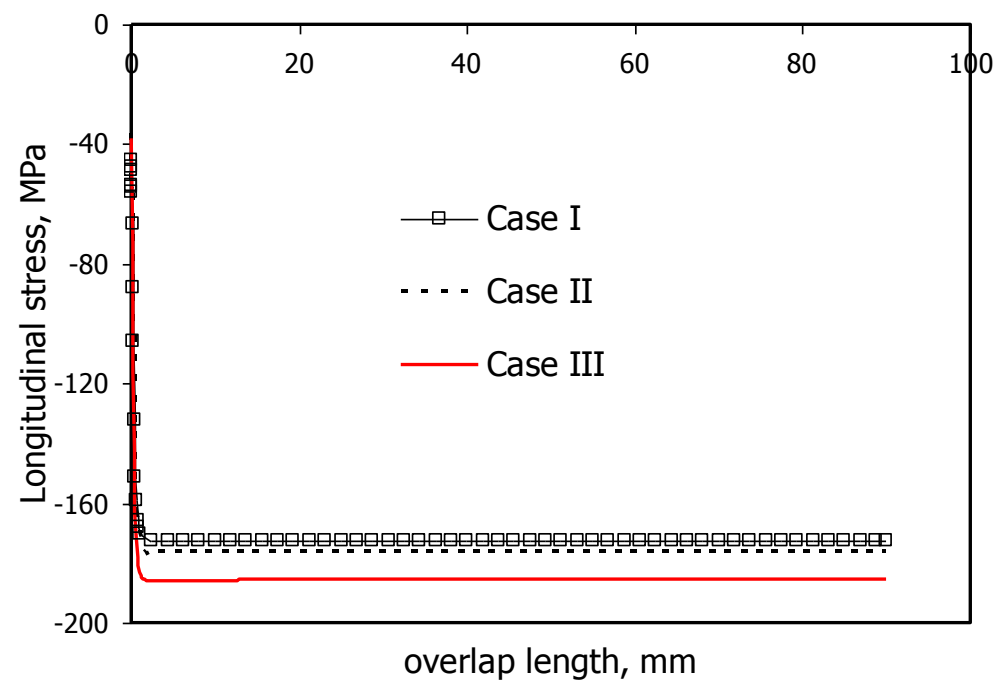

(a)

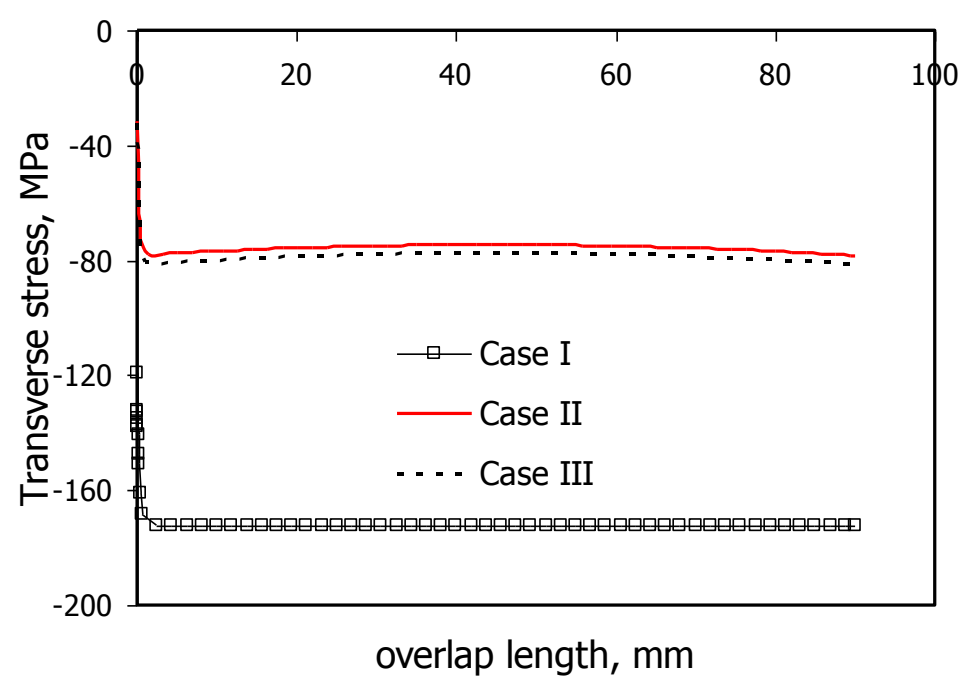

(b)

Figure 2. Comparison of stress predictions by the GPE model in the adherend for all analysis cases. (a) longitudinal stress $\left(\sigma_{\mathrm{xx}}\right)$ and (b) transverse stress $\left(\sigma_{\mathrm{zz}}\right)$. Sample edge and centre are at 0 and $90 \mathrm{~mm}$, respectively. 


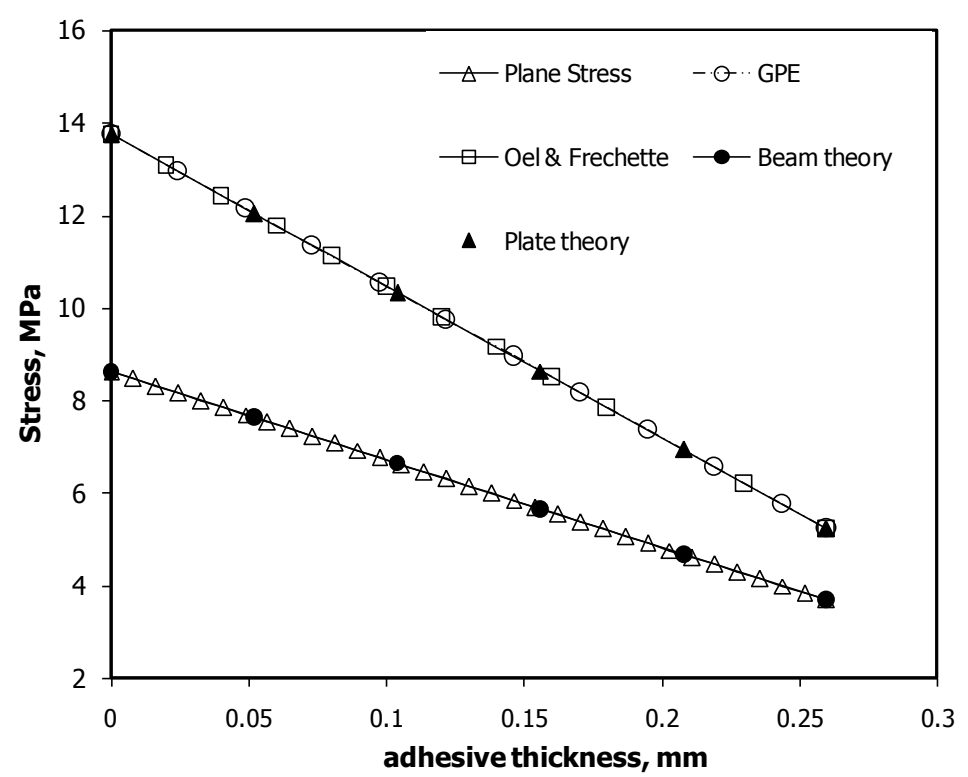

(a)

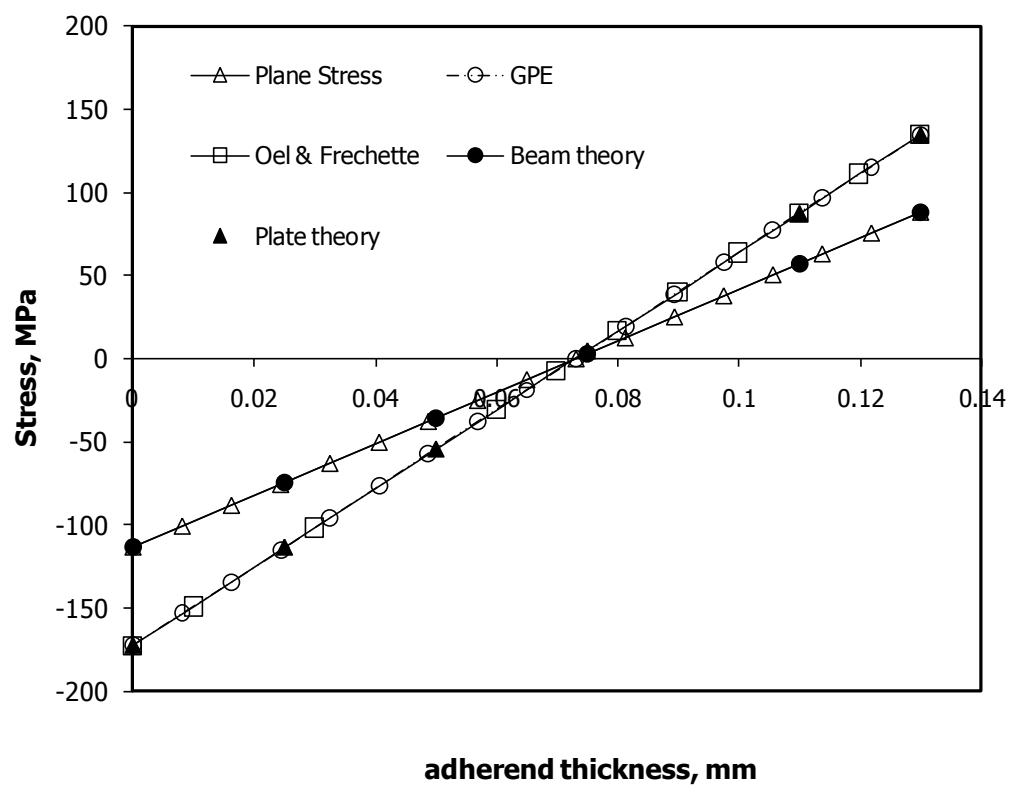

(b)

Figure 3. FEA vs. theory longitudinal stresses $\left(\sigma_{\mathrm{xx}}\right)$ comparison through the thickness of the strip in the (a) FM300-2M layer and (b) steel layer for Case I. Interface at $0 \mathrm{~mm}$. 


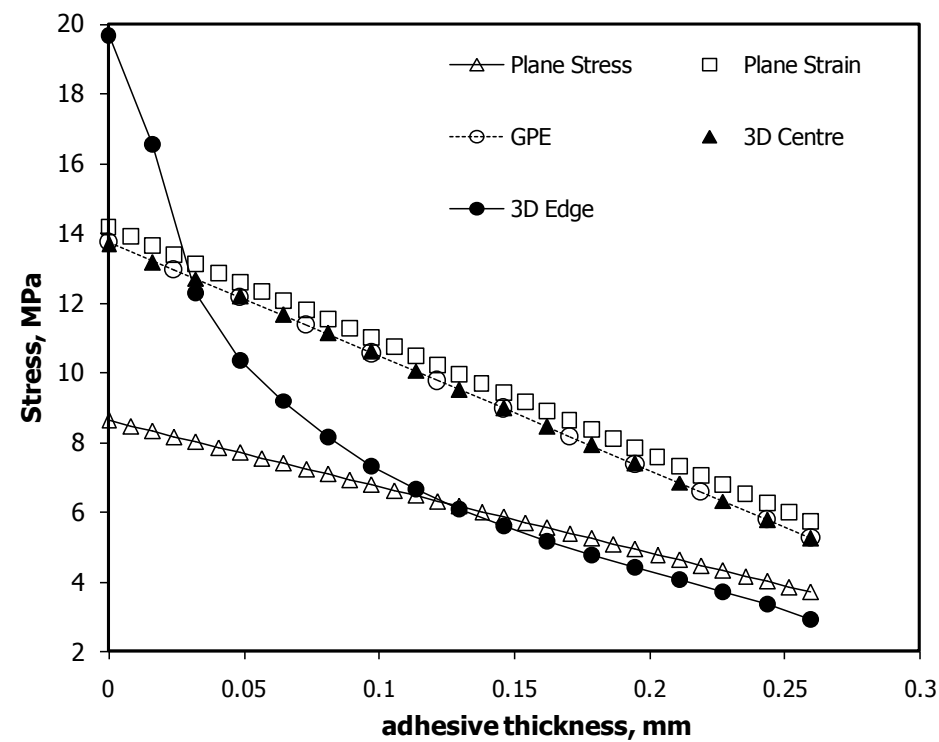

(a)

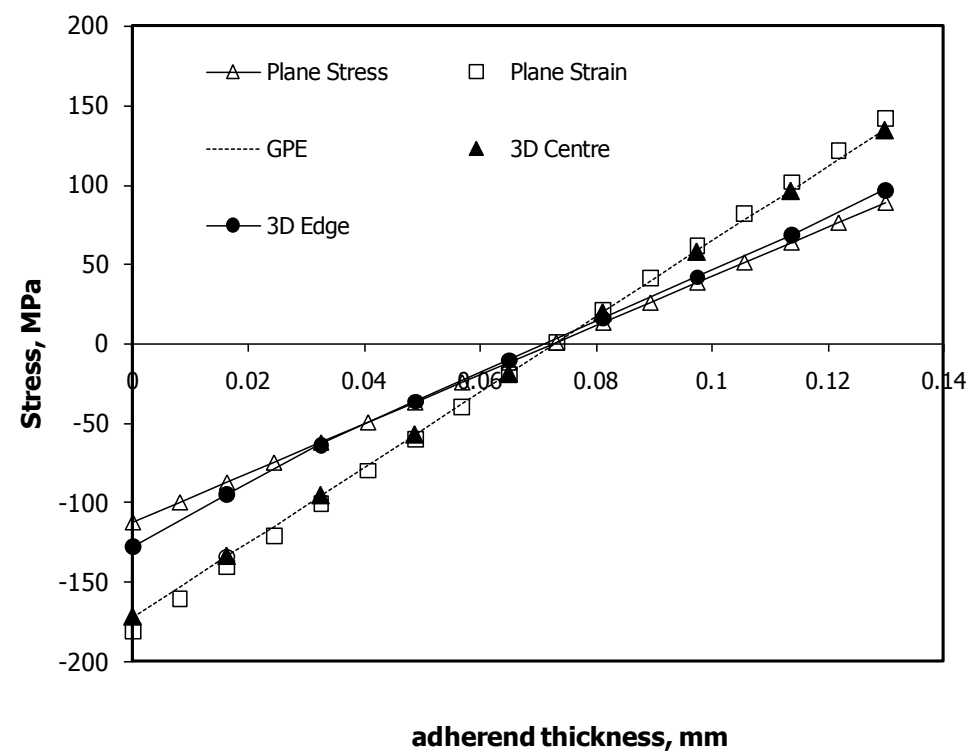

(b)

Figure 4. Longitudinal stress comparison $\left(\sigma_{\mathrm{xx}}\right)$ through the thickness of the strip for all $\mathrm{FE}$ models in the (a) FM300-2M layer and (b) steel layer for Case I. Interface at $0 \mathrm{~mm}$. 


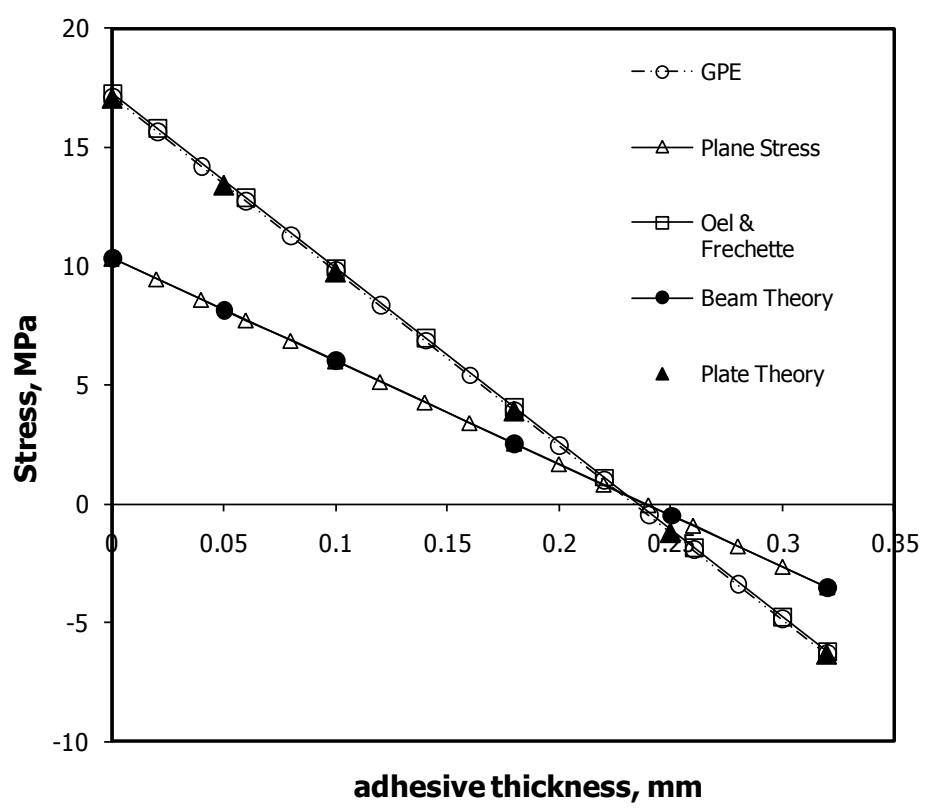

(a)

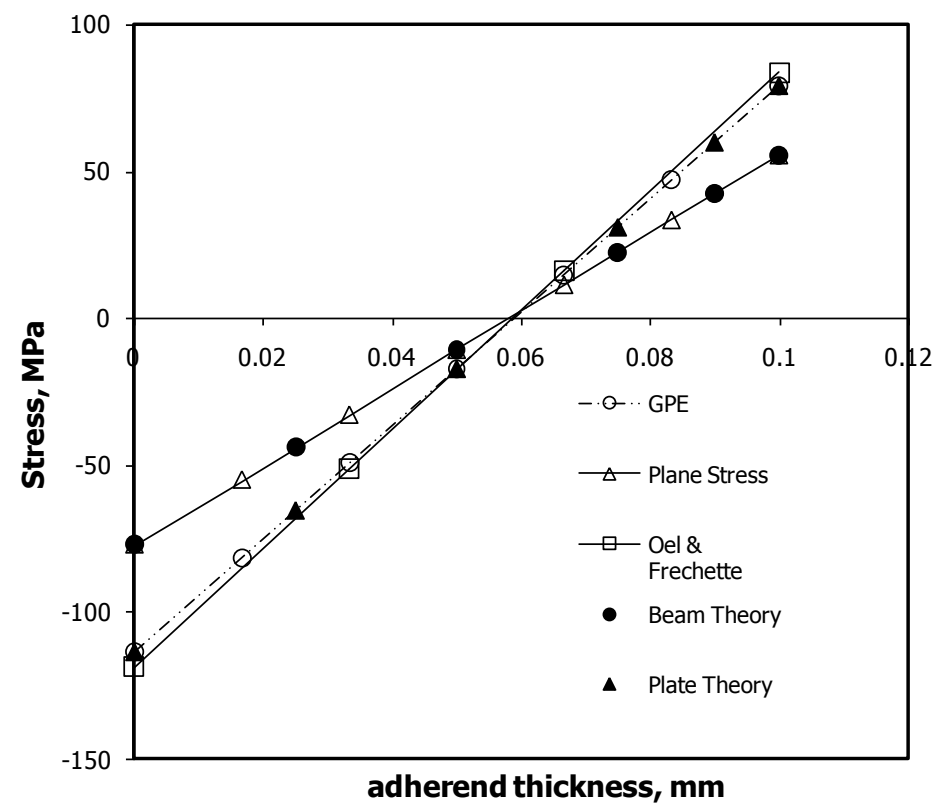

(b)

Figure 5. FEA vs. theory longitudinal stresses $\left(\sigma_{\mathrm{xx}}\right)$ across the strip width through the thickness of the strip (a) in the FM73 layer \& (b) in the aluminium layer for Case I. Interface at $0 \mathrm{~mm}$. 


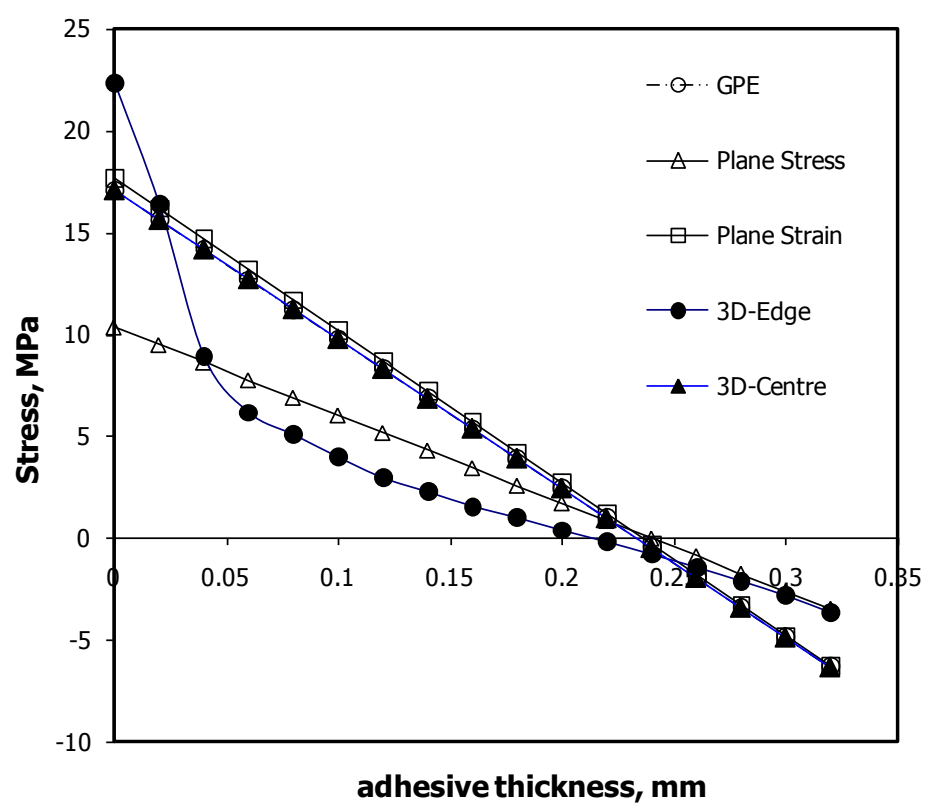

(a)

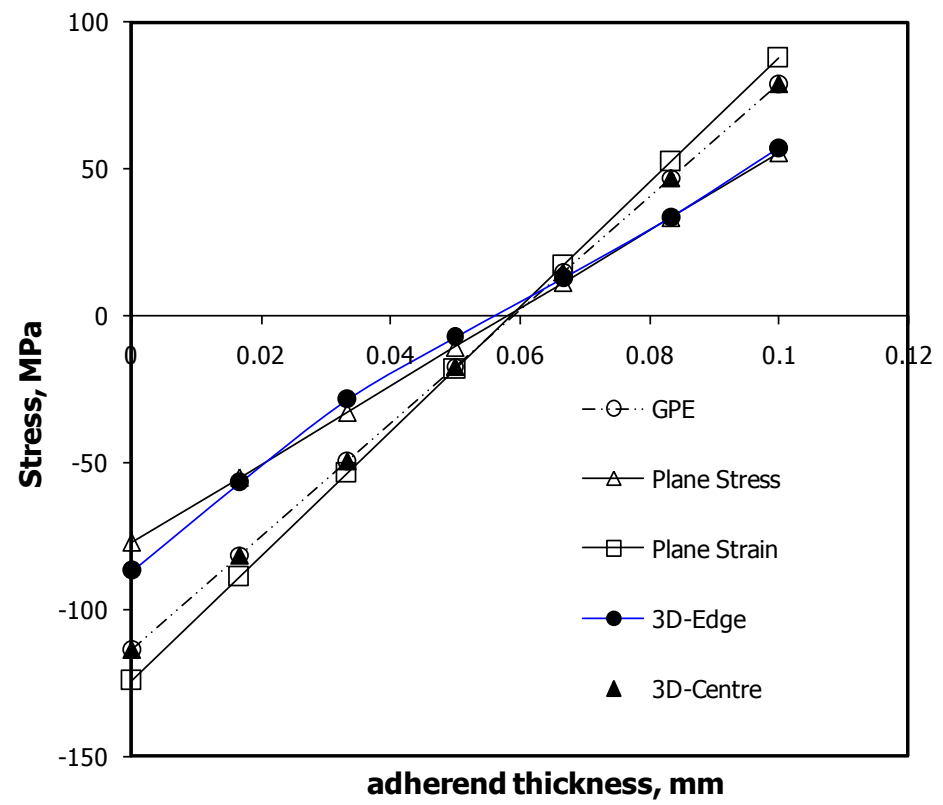

(b)

Figure 6. Longitudinal stresses $\left(\sigma_{\mathrm{xx}}\right)$ across the strip width through the thickness of the strip for all FE models (a) in the FM73 layer \& (b) in the aluminium layer for Case I. Interface at $0 \mathrm{~mm}$. 


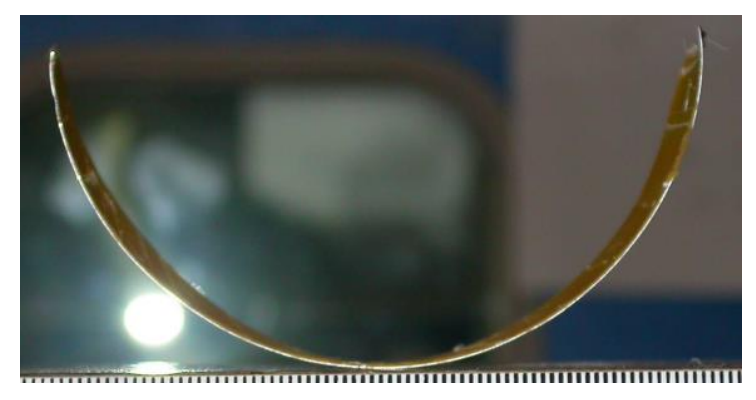

(a)

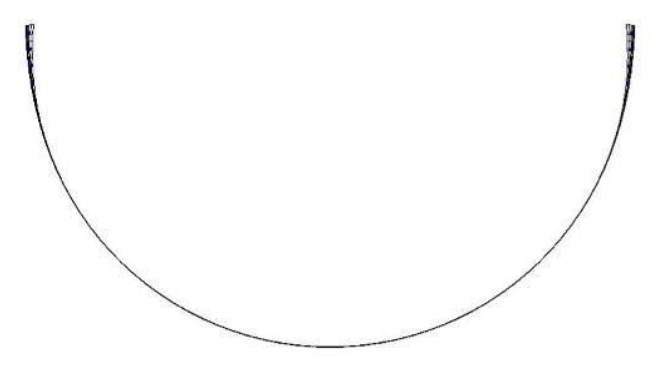

(b)

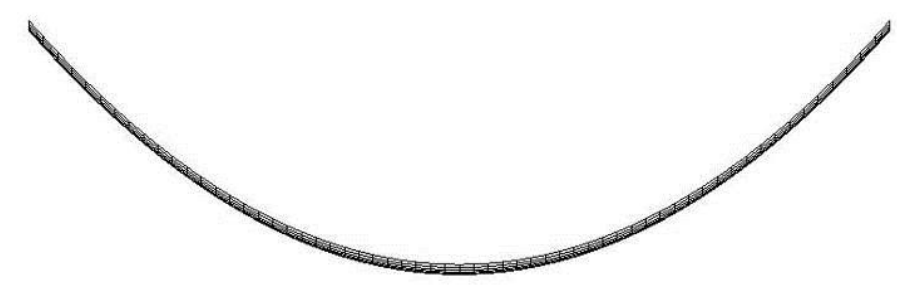

(c)

Figure 8. Deformed bending profiles for the Al/FM73 bi-material strip for (a) experimental, (b) Case III and (c) Case I at $20^{\circ} \mathrm{C}$

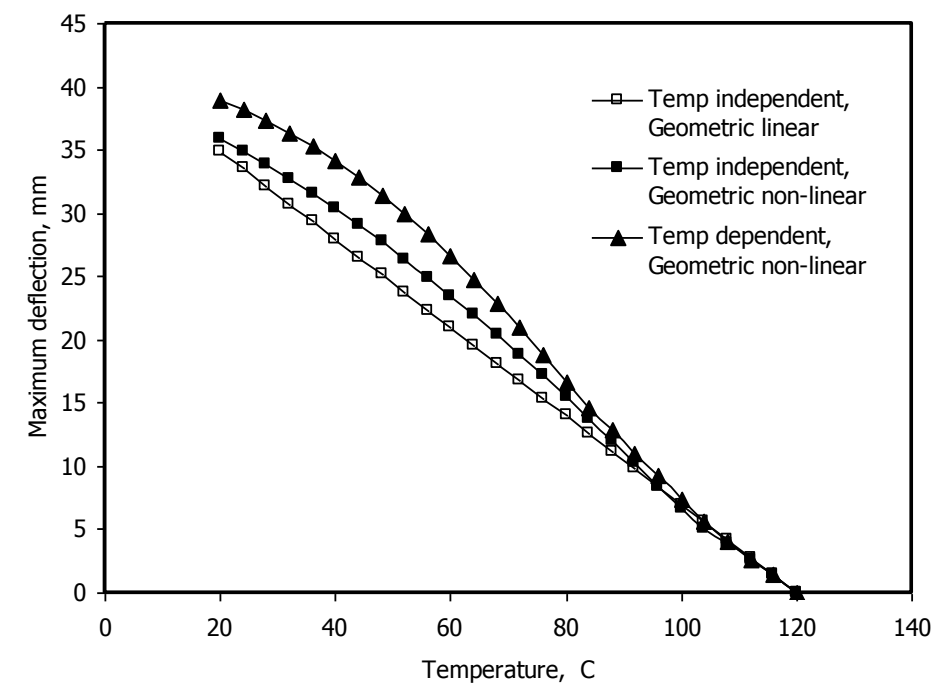

Figure 9. Evolution of maximum deflection with temperature for the analysis cases 


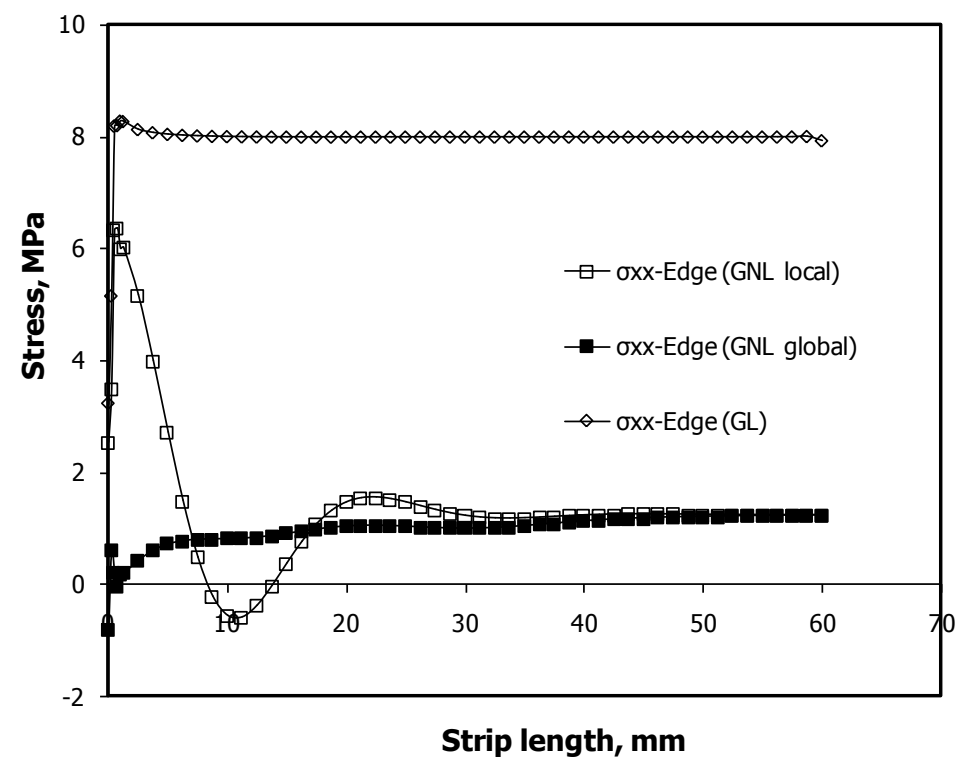

(a)

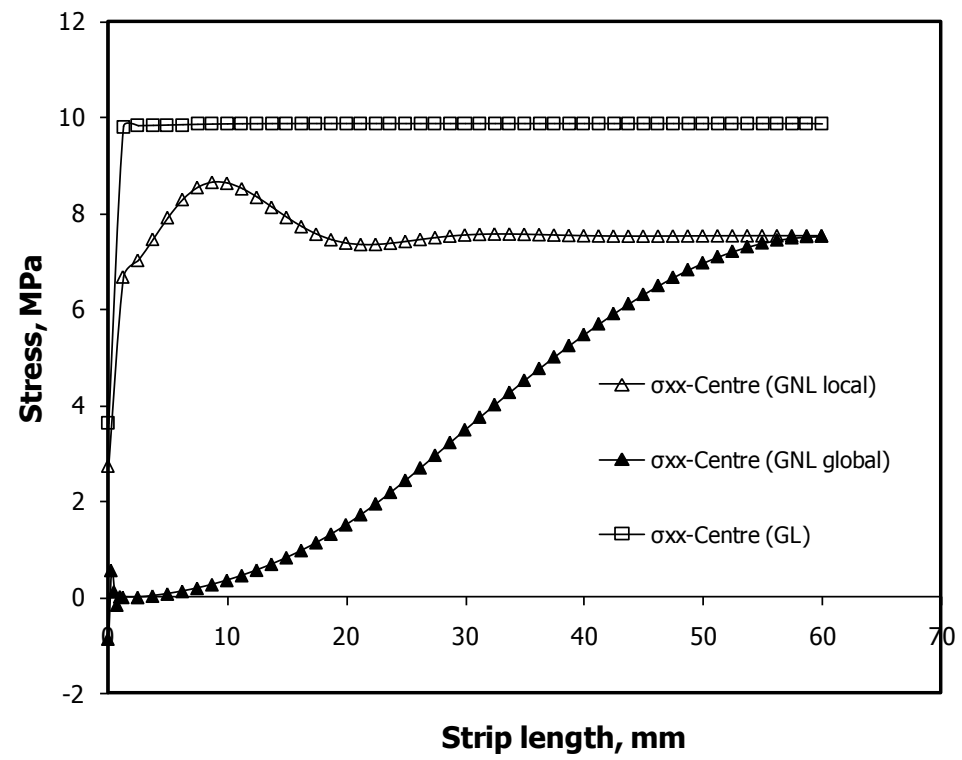

(b)

Figure 10. Comparison of longitudinal stresses $\left(\sigma_{\mathrm{xx}}\right)$ in the FM73 layer of the Al/FM73 bimaterial strip for geometric linear, geometric non-linear (global coordinates) and geometric non-linear (local coordinates) at (a) the edge and (b) the centre of the strip width. 


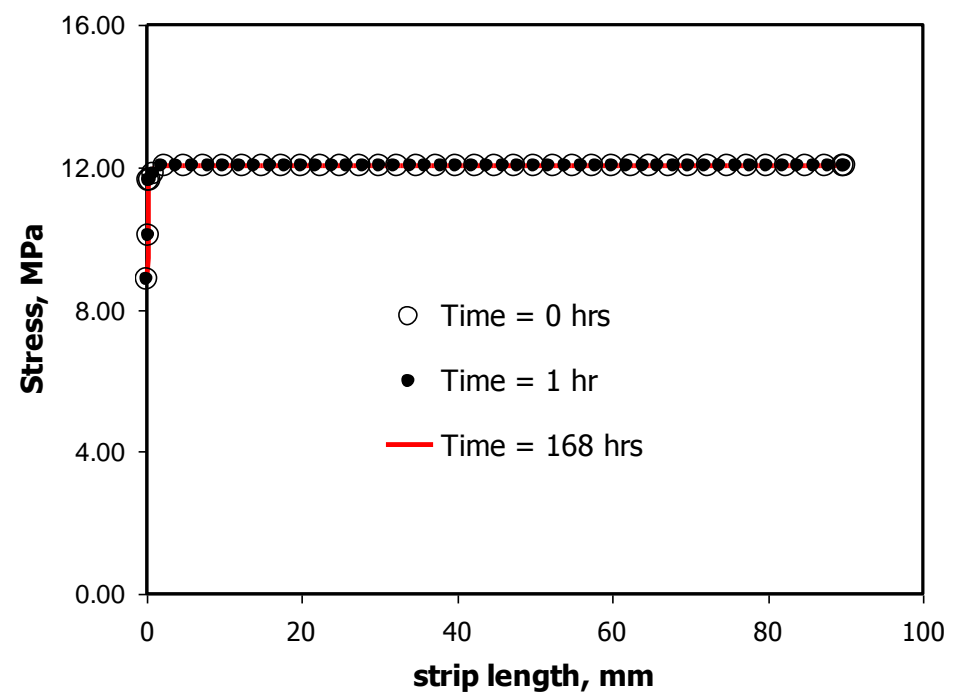

(a)

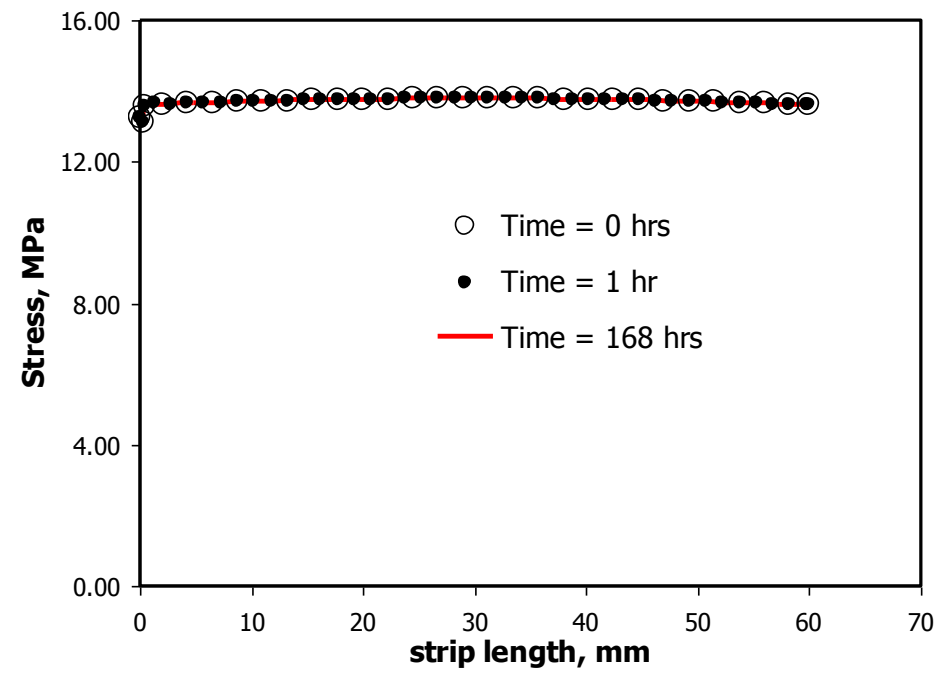

(b)

Figure 11. Prediction of von Mises stress from the creep analysis across the overlap length for (a) steel/FM300 bi-material strip and (b) Al/FM73 bi-material strip 

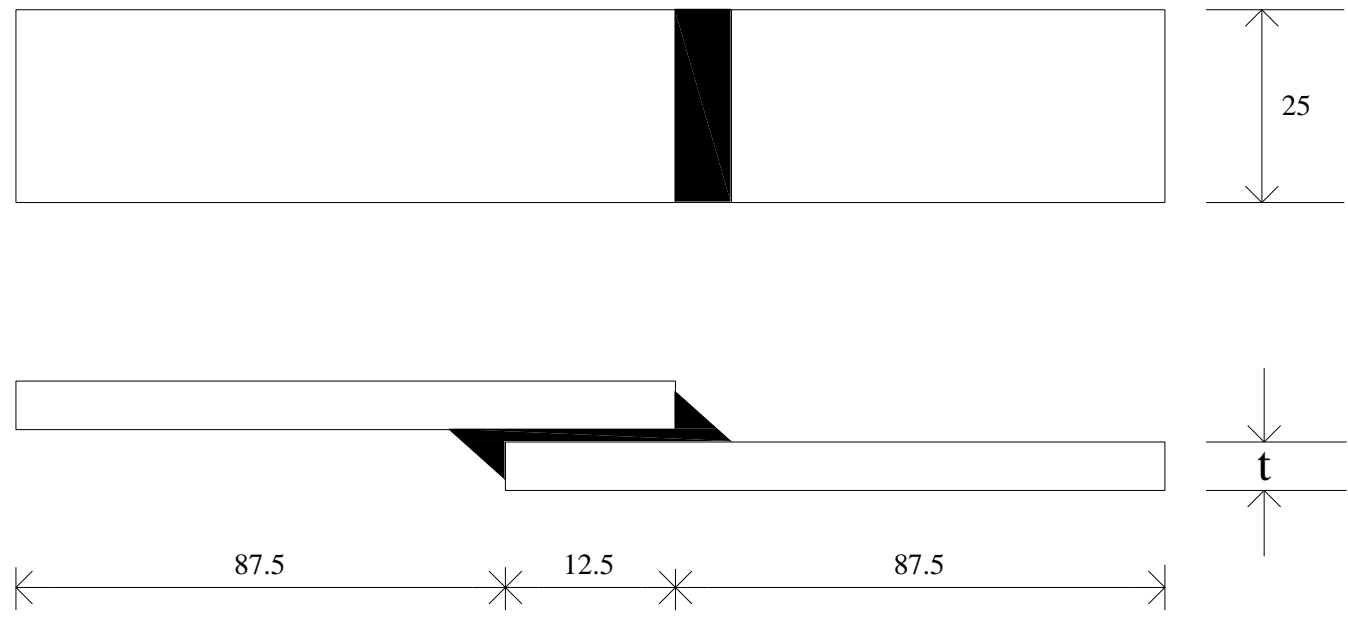

(a)
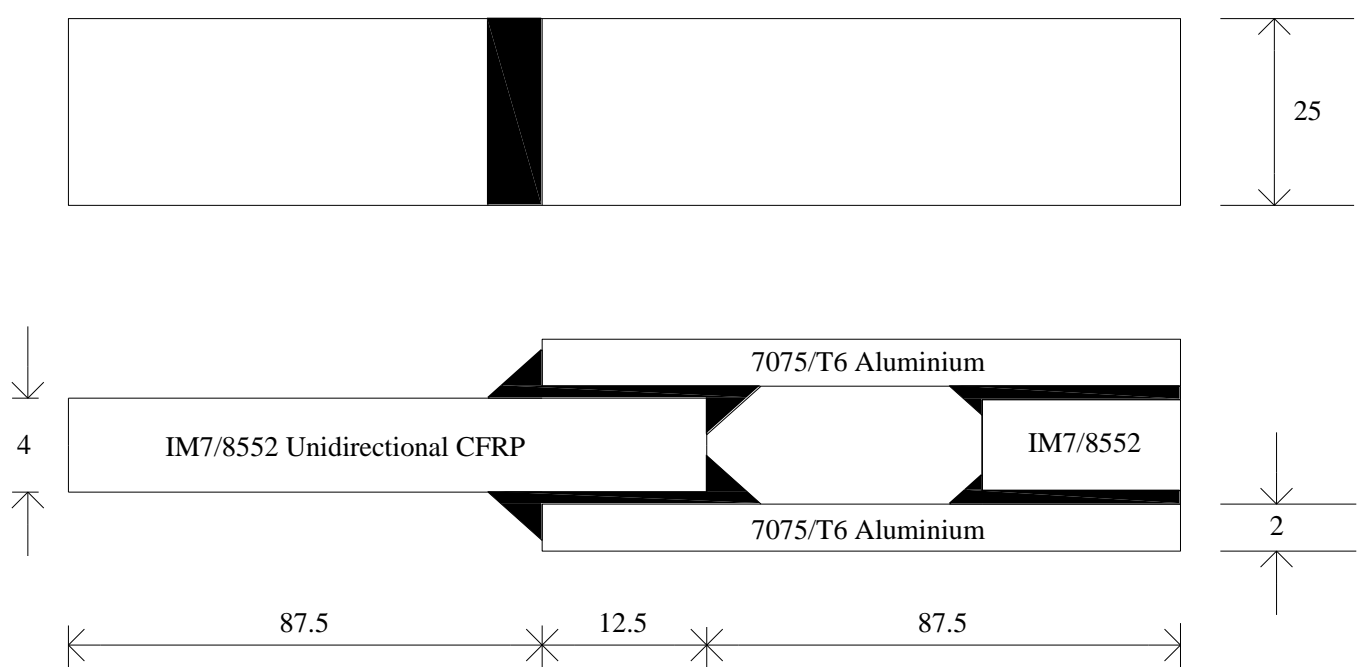

(b)

Figure 12. Dimensions of (a) the $7075 \mathrm{~T} 6$ aluminium/FM73 adhesive single lap joint and (b) the CFRP/Al/FM73 double lap joint. Dimensions in mm. 

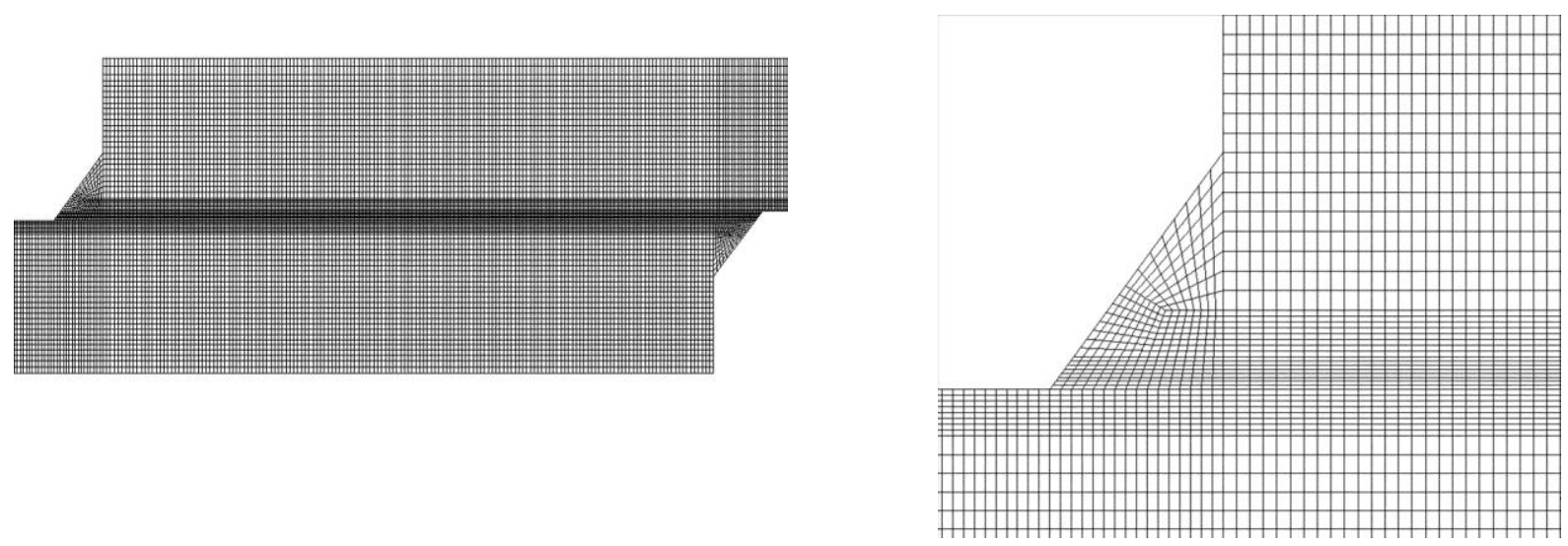

(a)

(b)

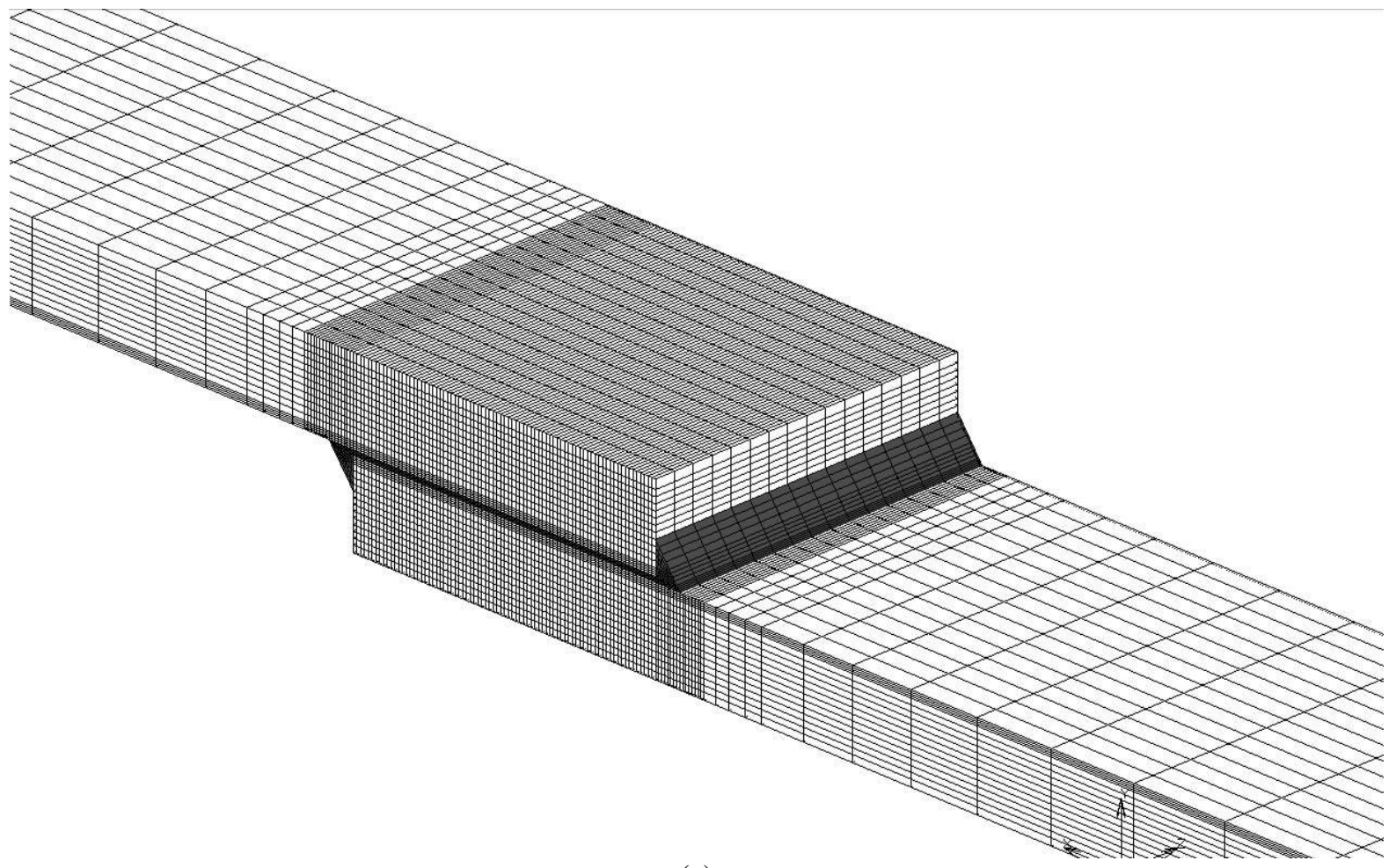

(c)

Figure 13. FE mesh for (a) 2D, (b) 2D fillet area and (c) 3D single and double lap joint models
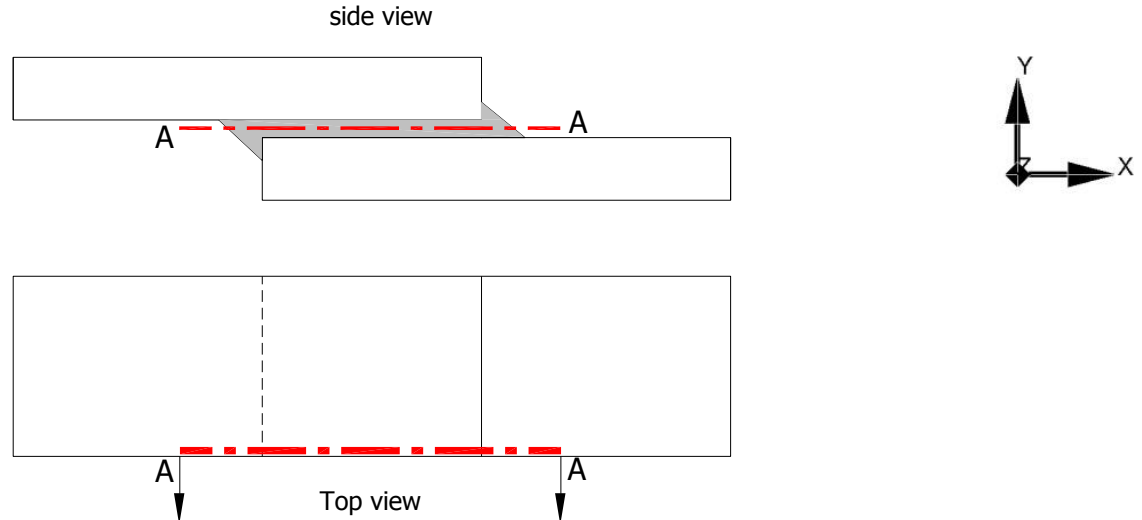

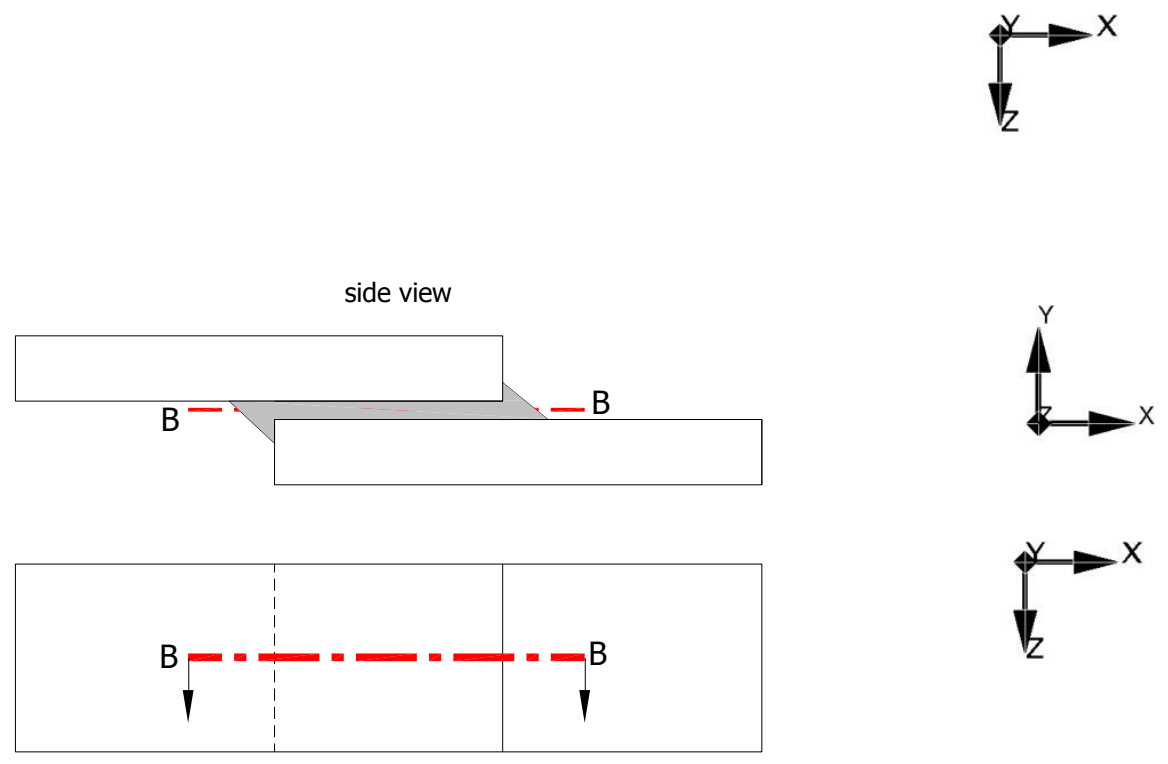

Top view
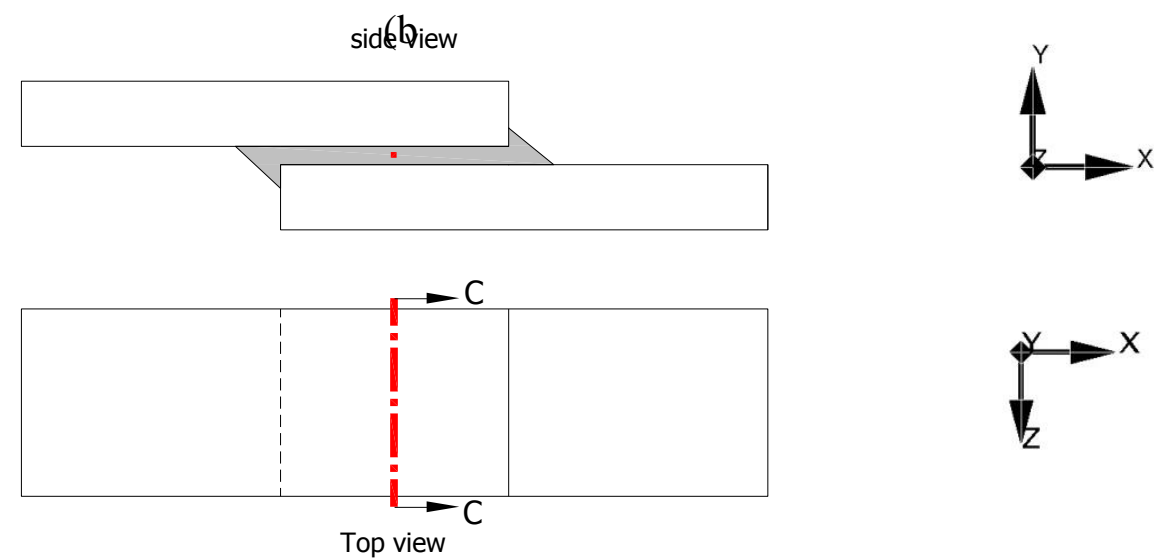

(c

Figure 14. (a) 'A-A' profile indicates the region where line plots along the overlap length at the edge are taken. (b) 'B-B' profile indicates the region where line plots along the overlap length at the centre are taken $(\mathrm{c}){ }^{\prime} \mathrm{C}-\mathrm{C}$ ' profile indicates the region where line plots across the overlap width at the centre are taken 


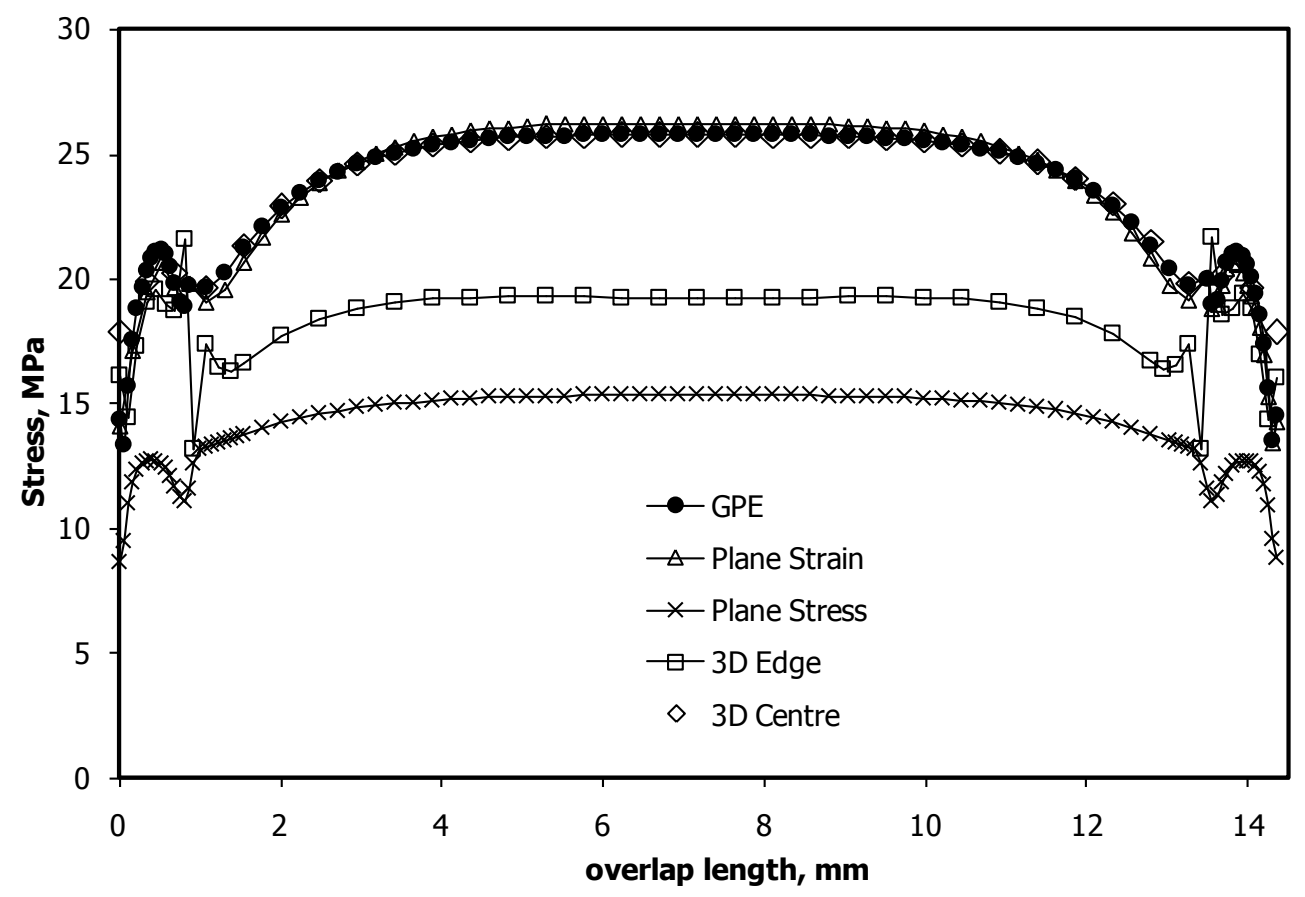

(a)

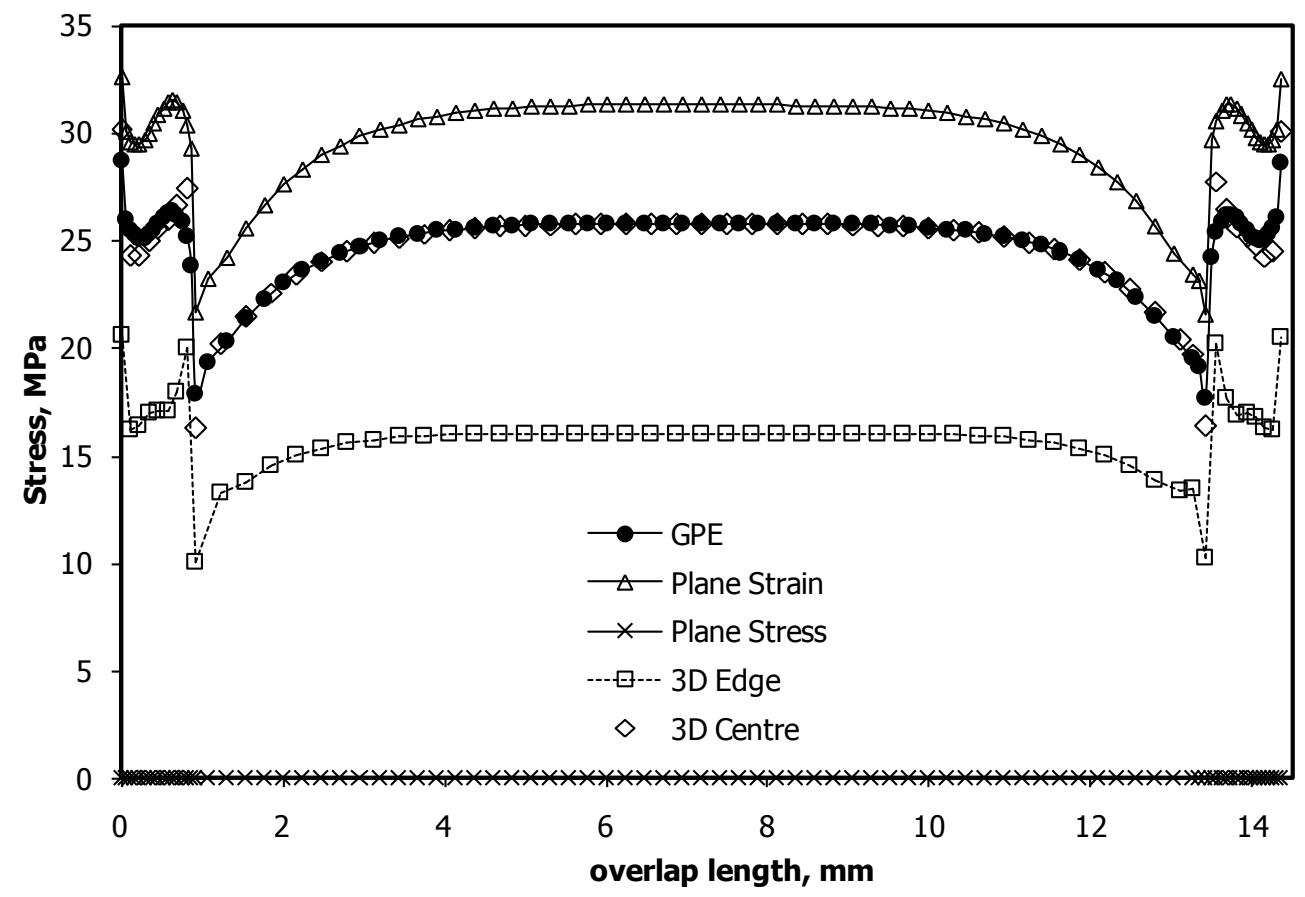

(b)

Figure 15. Stress comparisons in the adhesive layer in the aluminium single lap joint for (a) $\sigma_{\mathrm{xx}}$ and (b) $\sigma_{\mathrm{zz}}$. 


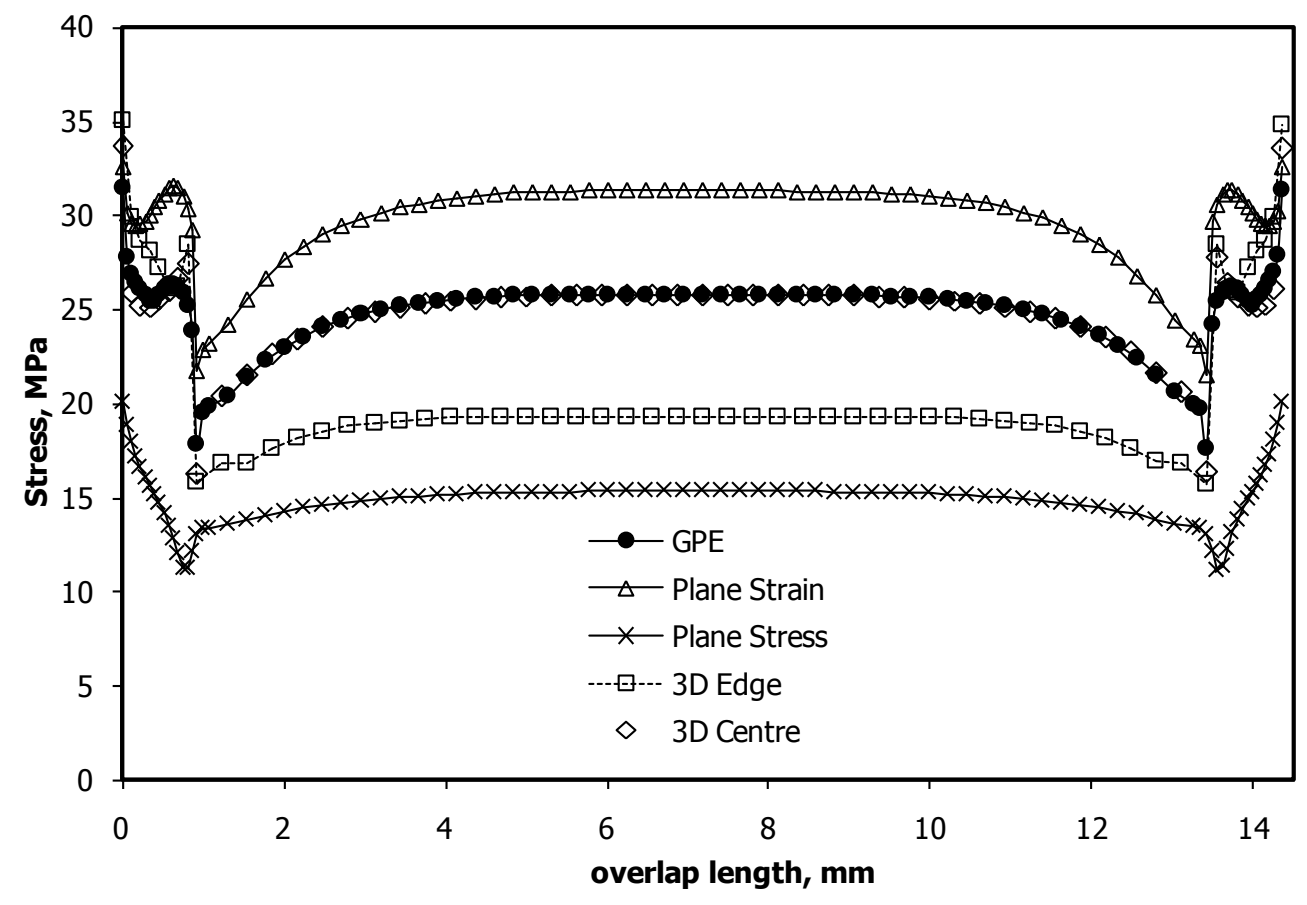

(a)

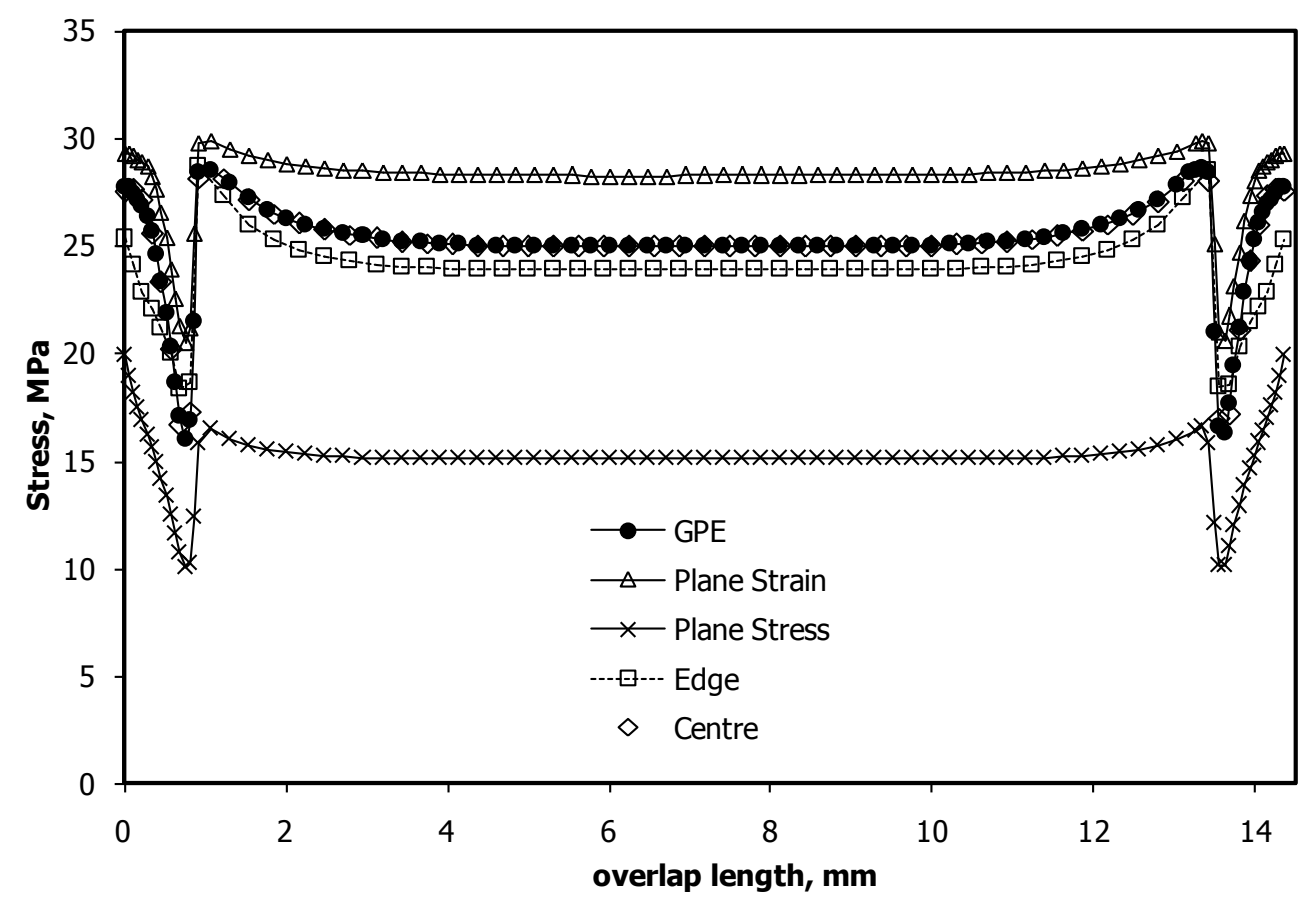

(b)

Figure 16. Stress comparisons in the adhesive layer in the Al/FM73 single lap joint for (a) maximum principal stress and (b) equivalent von Mises stress. 


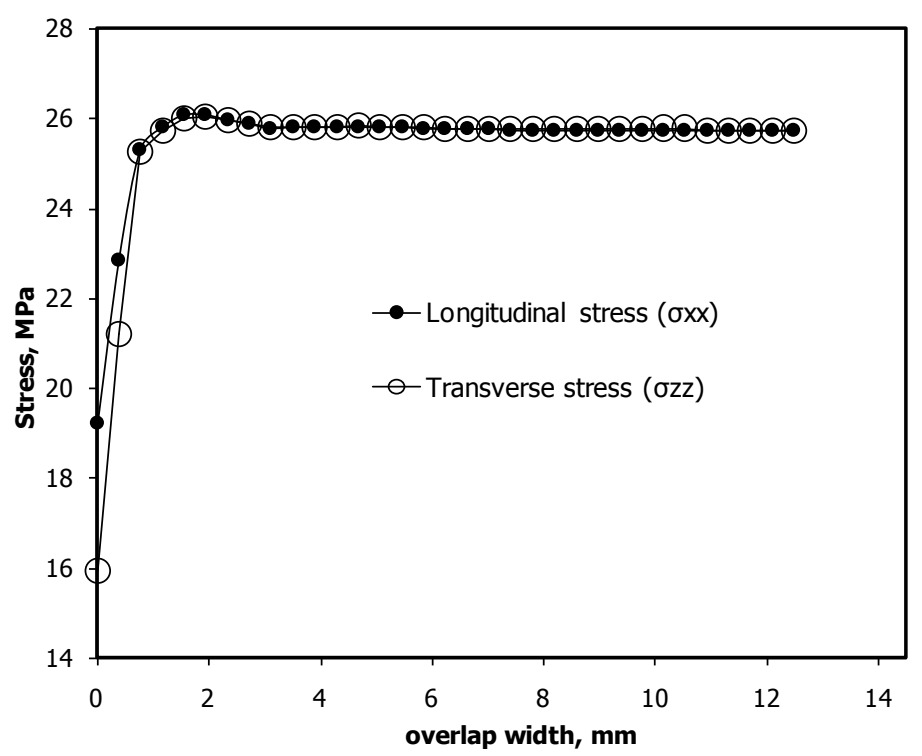

Figure 17. Longitudinal and transverse stress across the overlap width of the adhesive layer in the aluminium/FM73 single lap joint for the 3D model. Half width model with edge at $0 \mathrm{~mm}$ and middle at $12 \mathrm{~mm}$,
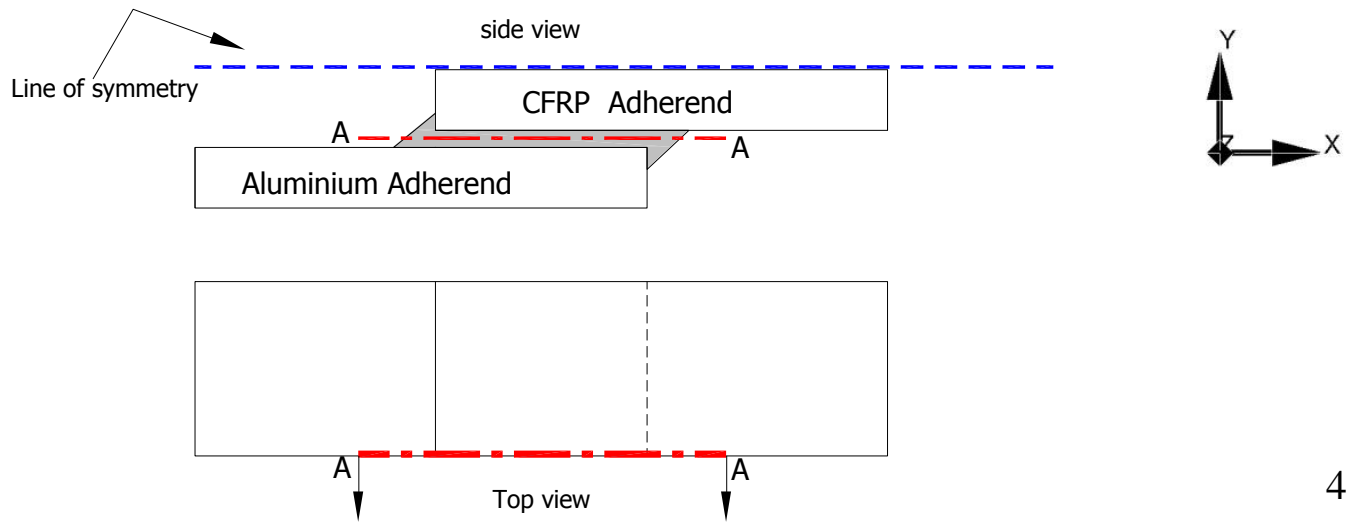

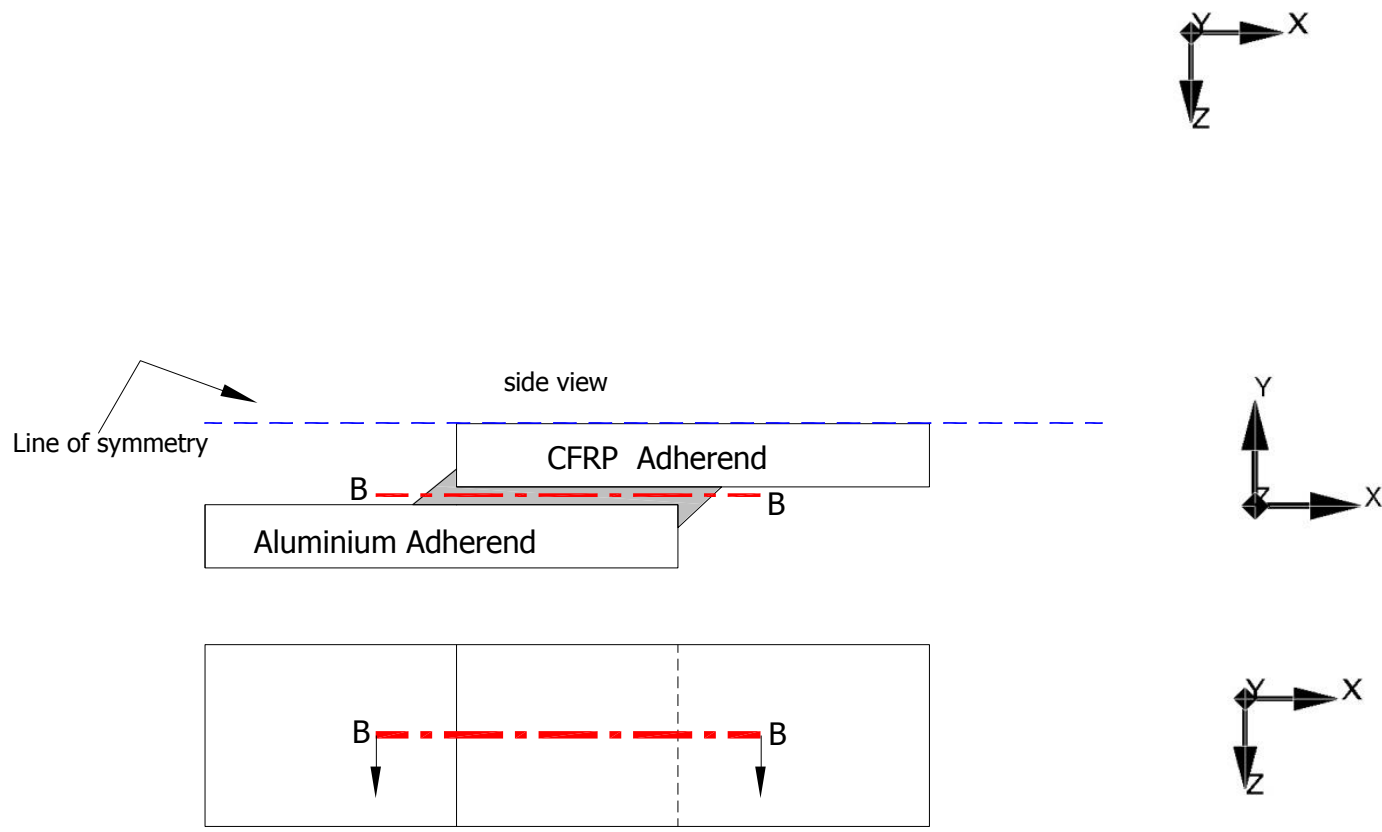

Top view

$(\mathrm{b}$

Figure 18. (a) 'A-A' profile indicates the region where line plots along the overlap length at the edge are taken, (b) 'B-B' profile indicates the region where line plots along the overlap length at the centre are taken. 


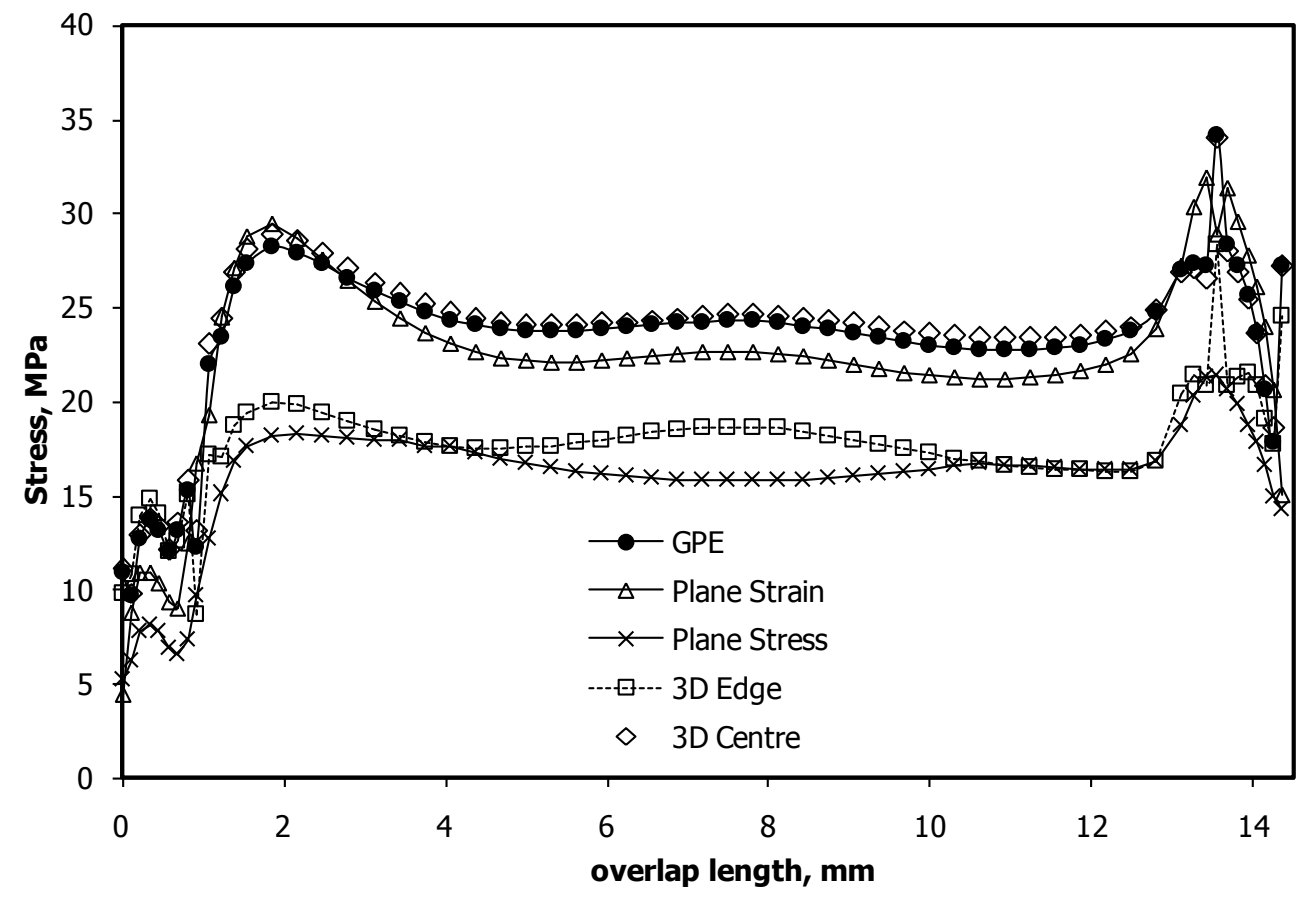

(a)

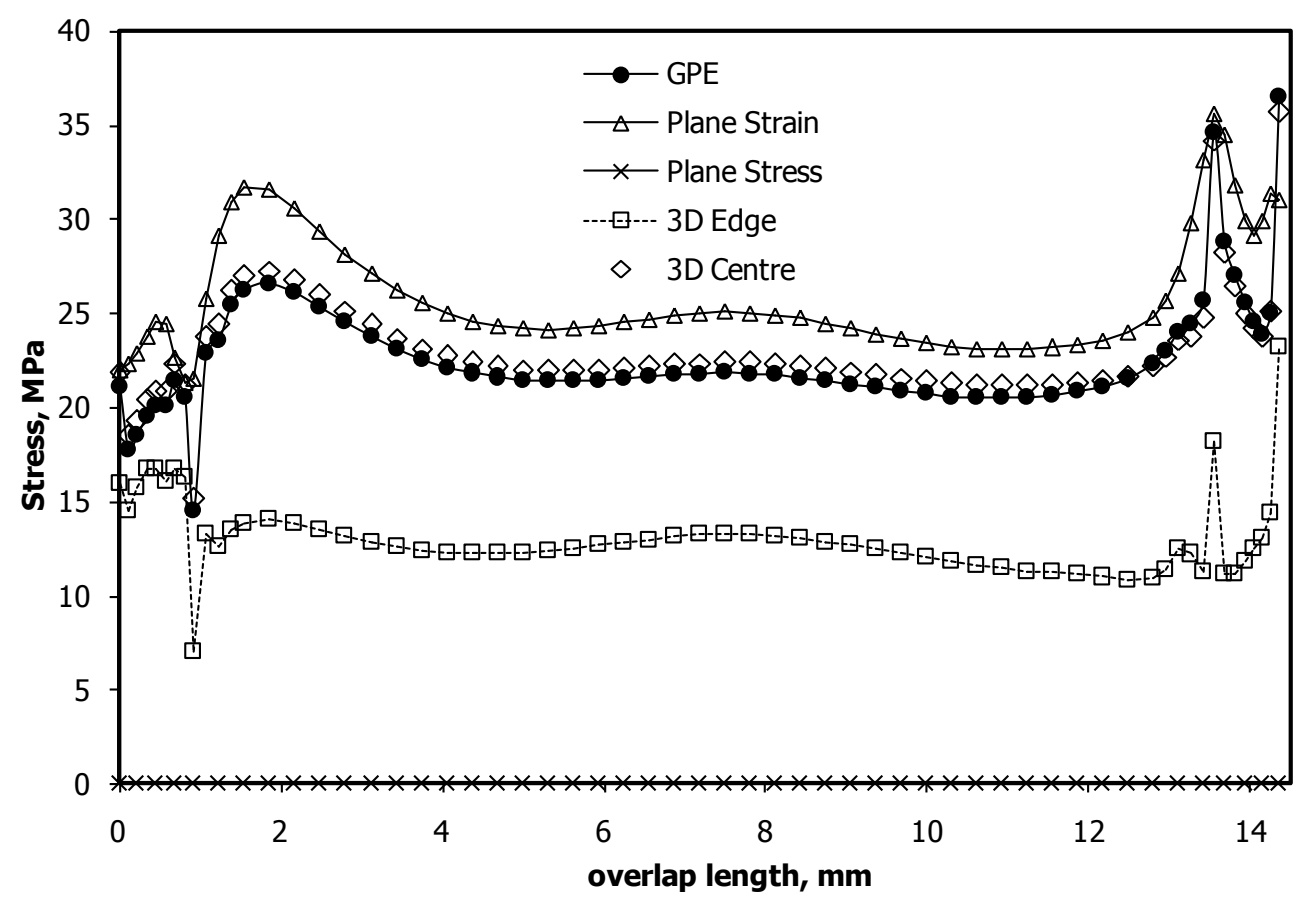

(b)

Figure 19. Longitudinal stress comparisons in the adhesive layer in the CFRP/Al double lap joint for (a) $\sigma_{\mathrm{xx}}$ and (b) $\sigma_{\mathrm{zz}}$. 

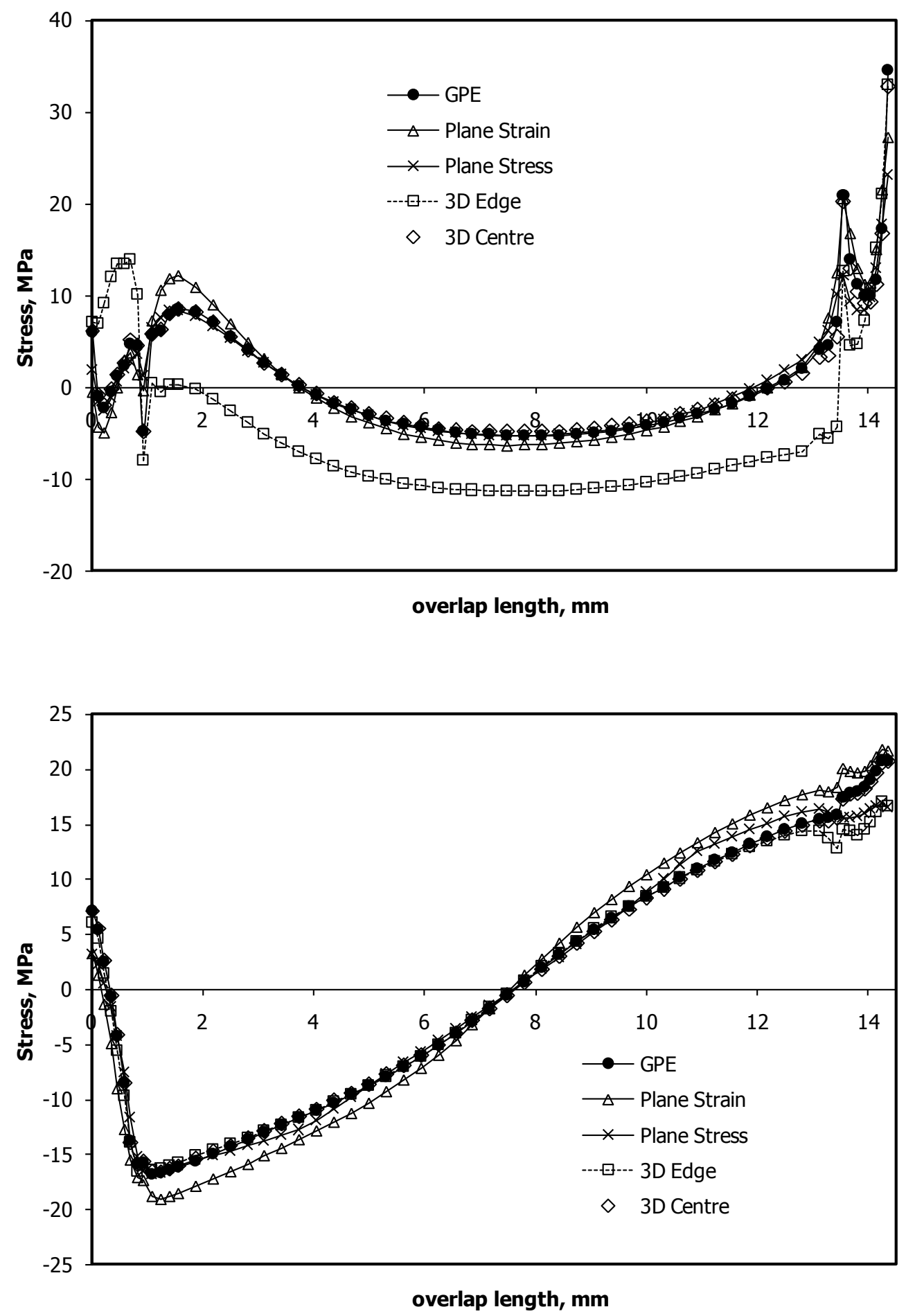

Figure 20. Stress comparisons in the adhesive layer in the CFRP/Al double lap joint for (a) $\sigma_{y y}$ and (b) $\tau_{\mathrm{xy}}$. 


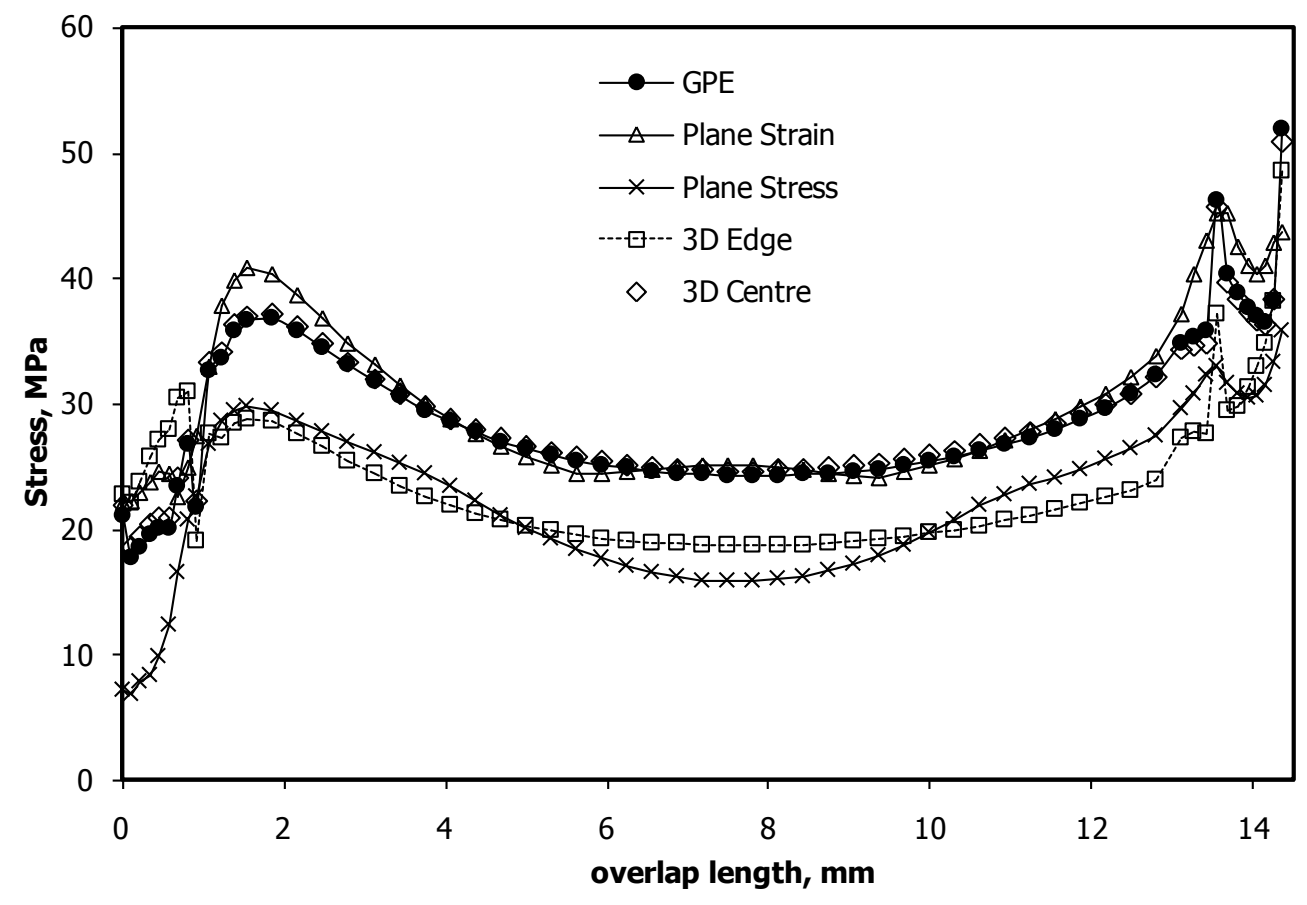

(a)

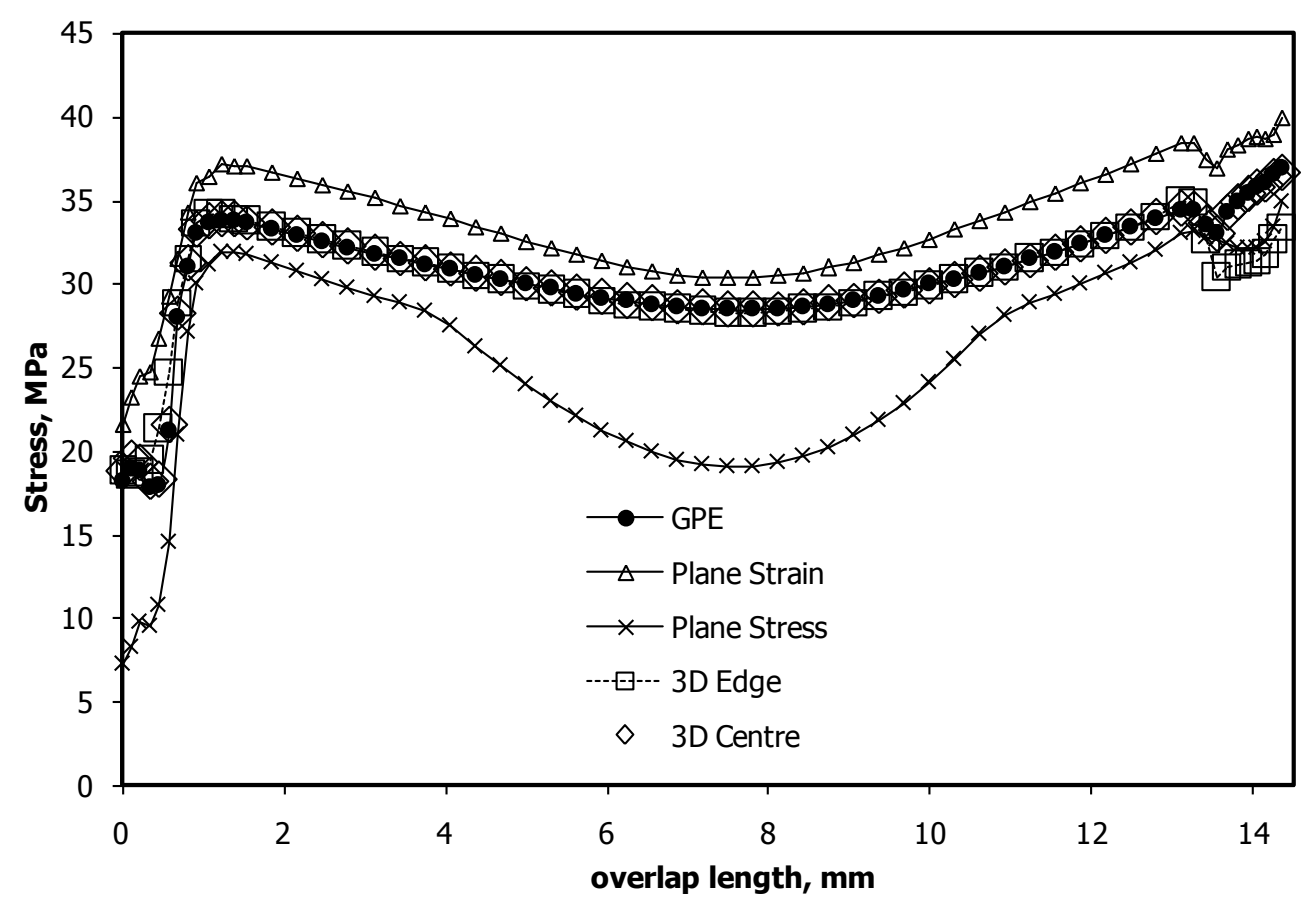

(b)

Figure 21. Stress comparisons in the adhesive layer in the CFRP/Al double lap joint for (a) maximum principal stress and (b) equivalent von Mises stress 

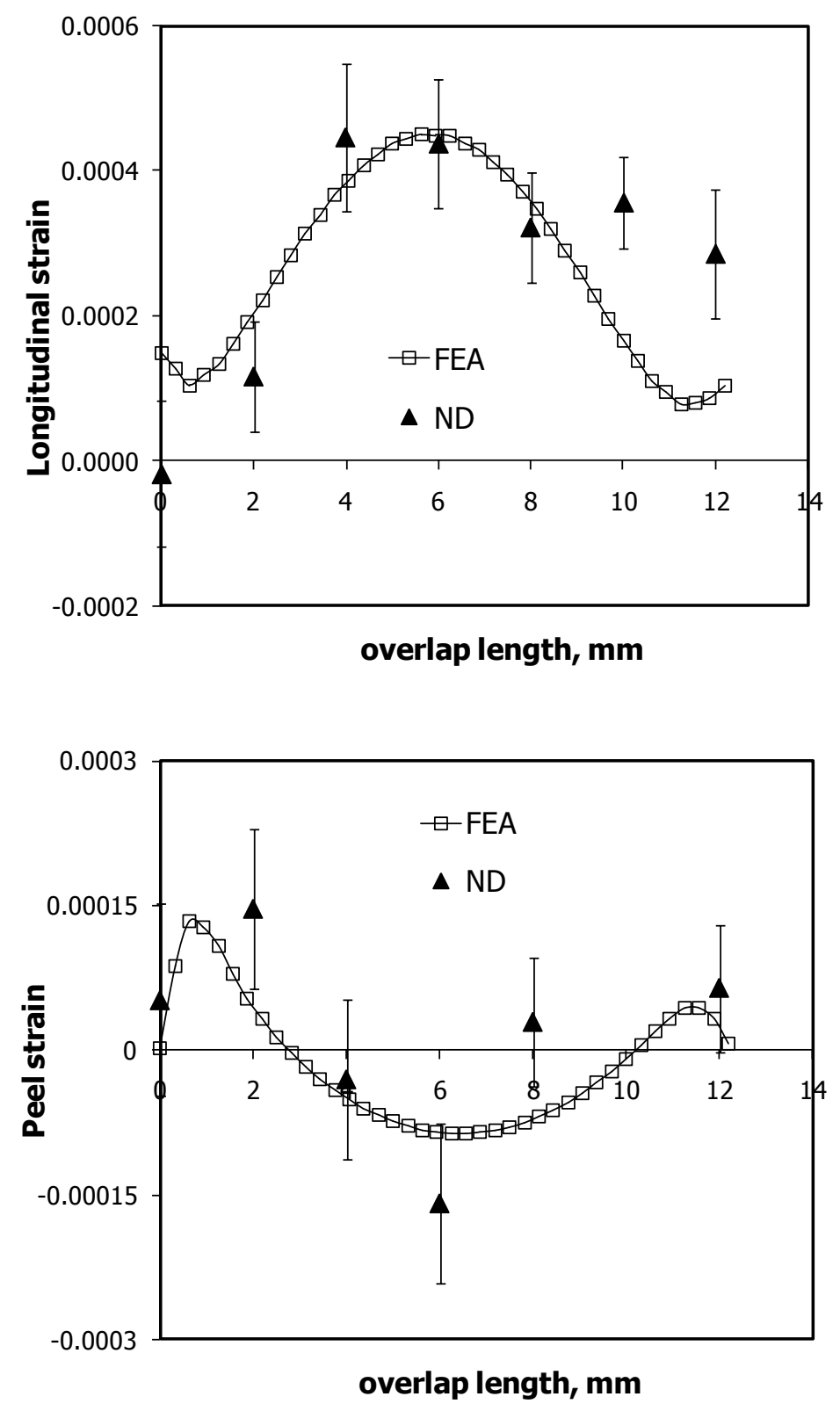

Figure 22. Comparison of predicted thermal residual strains and measured strains from neutron diffraction experiments in the upper aluminium adherend of the CFRP/Al/FM73 DLJ showing (a) longitudinal strain and (b) peel strain. 